\title{
APROXIMACIÓN HISTÓRICA A LA EDUCACIÓN FORMAL E INFORMAL DEL AUDIOVISUAL EN CANARIAS
}

\author{
Attua Alegre Paiz \\ Director de Alisios. Revista del Audiovisual Canario
}

\section{RESUMEN}

En Canarias, como en el resto del territorio nacional, el sistema educativo ha prestado poca atención a la educación del audiovisual. Este hecho afecta a las capacidades críticas del espectador ante los contenidos que realizan distintos medios de comunicación, lo que aumenta la influencia que estos ejercen en el receptor. Este trabajo realiza una aproximación histórica a los distintos hitos que han conformado la educación formal e informal sobre el audiovisual en Canarias, con el objetivo de analizar si han sido suficientes y, en caso contrario, sugerir de qué manera se puede corregir dicha situación.

Palabras Clave: Canarias, educación, comunicación audiovisual, educación audiovisual, LOGSE, LOE, LOMCE, competencia digital.

\section{AUDIOVISUAL EDUCATION IN THE CANARY ISLANDS. HISTORICAL APPROACH TO FORMAL AND INFORMAL AUDIOVISUAL EDUCATION IN THE CANARY ISLANDS}

\section{Abstract}

Both in the Canary Islands and mainland Spain, audiovisual communication has had little relevance in the school syllabus. Critical skills have not been developed, making spectators more easily biased by the contents published in the media. This study is a historical approach to the main features that have characterized audiovisual contents in the Canary islands both in formal and informal education. Our aim is to analyze these contents and, depending on the results, suggest how to improve the situation.

KEYwORDs: Canary Islands, education, audiovisual communication, audiovisual education, LOGSE, LOE, LOMCE, digital competence.

DOI: http://doi.org/10.25145/j.latente.2018.16.002

Revista Latente, 16; diciembre 2018, pp. 37-82; ISSN: e-2386-8503 


\section{INTRODUCCIÓN}

Ante la aceleración vertiginosa de nuestro tiempo, Internet, las TIC y los nuevos medios de comunicación han transformado las redes de interacción social y de influencia de la sociedad. En plena era de la información es fácil vivir desinformados ante la avalancha de contenidos que nos golpean repetidas veces durante cada jornada. Lo icónico ha alterado nuestro imaginario colectivo, y lo audiovisual, hoy, está más presente en nuestra vida que en ningún otro tiempo pasado. 120 años después del nacimiento del cine, el vídeo (ahora digital) se ha impuesto como el principal medio para la comunicación.

El cine, la televisión y los nuevos paradigmas que impone la red, con YouTube al frente de lo puramente audiovisual -así como los videoclubs online-, constituyen los principales actores mediáticos a los que se somete una gran parte de la sociedad, especialmente la más joven, al no interactuar estrechamente con la prensa ni la radio. Por esta razón parece importante plantearse una pregunta: ¿estamos preparados para interactuar libremente con los contenidos que estos medios ofrecen?

No hay duda de que para alcanzar una sociedad democrática esta debe estar conformada por ciudadanos libres, con capacidad crítica y un escepticismo siempre perenne en lo que respecta a los contenidos expuestos por los medios de comunicación. Ante este hecho, ¿quién o qué educa a la sociedad para alcanzar dicho grado de libertad y juicio crítico?

La escuela, una vez más, parece constituir ese espacio en el cual se intenta educar a ciudadanos capaces, no solo de analizar críticamente el contenido de los medios, sino de poder expresarse a través de los mismos. Sin embargo, lejos de alcanzar esta realidad, la educación formal no se ha preocupado lo suficiente por garantizar que tal hecho se dé. De hecho, lo audiovisual -y qué decir del cine- ha sido tradicionalmente tratado como un elemento carente de interés académico. No obstante, poco a poco ha ido acaparando su espacio dentro y fuera de la educación reglada; aunque no el suficiente o necesario.

En el caso de Canarias esta realidad es, si cabe, aún más cruda, aunque no exenta de hitos importantes que han querido llevar lo audiovisual a las aulas, y mucho más lejos, a la totalidad de la sociedad. Sin embargo, ¿`ómo han sido las enseñanzas del audiovisual en Canarias? ¿El Archipiélago cuenta con una formación superior suficiente como para dotar de profesionales a un sector tan importante en el siglo XxI como el audiovisual? ¿Qué se puede hacer para dotar a la sociedad de un mejor conocimiento sobre la comunicación y su uso?

El presente texto pretende ser una primera aproximación a la evolución histórica que han llevado las distintas enseñanzas y ofertas educativas relacionadas con lo audiovisual (y especialmente el cine) en Canarias. Partiendo de la idea de que el sistema educativo no se ha preocupado lo suficiente o de la manera correcta sobre la educación audiovisual, intentaremos hallar también aquellas iniciativas con éxito o que por su esfuerzo y dedicación merecen ser reconocidas dentro de tales labores formativas. Por último, al final de las conclusiones se exponen brevemente, y por medio de una serie de puntos, las distintas medidas que se sugieren para mejorar la situación en Canarias. 
La intención de este trabajo no ha sido otra que mostrar uno de tantos déficits educativos que ha tenido la escuela española, y por ende la canaria, desde el franquismo hasta nuestra actualidad. Un pueblo sabio es un pueblo libre, y en los tiempos que corren la libertad es más necesaria que nunca si se quieren preservar y mejorar los derechos y valores de nuestras sociedades modernas. La educación, por tanto, es la herramienta perfecta para dotar de libertad a la ciudadanía, en este caso una libertad con respecto al objeto audiovisual y mediático, ya sea consumido en una sala de cine, en nuestro televisor o en algún medio digital a través de nuestro smartphone o cualquier medio venidero.

\section{ANTECEDENTES TEÓRICOS}

Sumergidos en la era de la información, no es sorprendente que existan, dentro y fuera de nuestras fronteras, multitud de trabajos, artículos y publicaciones que se han preocupado en aproximarse a la relación de los medios audiovisuales y la educación formal (e informal) de nuestra sociedad. Si bien es cierto que un gran porcentaje de estos textos suelen estar relacionados con el cine en el aula; por lo que se margina a otros medios de gran interés en nuestro tiempo, como puede ser la amplia red de espacios y medios sociales que surgen y desaparecen constantemente en Internet. No obstante, en el proceso de documentación de esta investigación se ha tomado con especial relevancia todo aquello que atañe al conocimiento del lenguaje audiovisual, que encuentra, todavía hoy, su mejor representación en el cine y, por extensión, en la esfera televisiva de las series, que gozan hoy de un enorme número de espectadores en todo el mundo.

En cualquier caso, lo que aquí se ha intentado realizar es una aproximación histórica al vínculo que ha existido en Canarias entre su sistema educativo y las enseñanzas (de cualquier tipo) relacionadas con el audiovisual, y más concretamente con el cine. Es por esta razón por la que en el proceso de documentación fue de marcada relevancia encontrar textos y trabajos que ya hubieran abordado con anterioridad esta cuestión. Sin embargo, una vez más, parece que la actividad de investigación se encuentra frustrada por navegar en solitario en mares que han sido surcados con anterioridad en muy pocas ocasiones. No obstante, lo que a continuación se expone comprende los pequeños tesoros que se han rescatado de las profundidades entre antiguos artículos publicados en algunas revistas, textos olvidados y algún trabajo de marcado interés.

Concretamente, han sido de gran utilidad el trabajo final de máster de Gabriel Trenzado Quintero, Educar la Mirada: análisis de un proyecto ${ }^{1}$, en el que someramente relata en qué consistía dicho proyecto educativo; diferentes artículos

1 Trenzado Quintero, G. (2016): Educar la Mirada: análisis de un proyecto. Trabajo final de máster de Cultura Audiovisual y Literatura. Universidad de Las Palmas de Gran Canaria. 
hallados en el imprescindible El cine en Canarias (Una revisión critica) ${ }^{2}$ y firmados, en este caso, por Rolando Díaz, Domingo Sola Antequera y Josep M. Vilageliu; la información contenida en Yaiza Borges: aventura y utopia ${ }^{3}$, que hace referencia a la actividad didáctica de dicho colectivo, y otros textos de menor interés y que no se aproximan explícitamente a la esfera educativa, como fue el caso de Los cine-clubes Universitario y Náutico [1953-1969] .

\subsection{El audiovisual en Canarias: diversos puntos de atención}

Antes de comenzar a señalar lo que otros autores han dejado en herencia con respecto a la cuestión del audiovisual en la educación canaria, es oportuno recordar las peculiaridades culturales que han definido históricamente a la relación entre el cine (máxima representación de los medios audiovisuales) y la sociedad isleńa.

Como bien sabrá el lector, el cine en Canarias ha sido, desde su llegada a las Islas en $1896^{5}$, un medio que ha despertado numerosas pasiones individuales y colectivas desde entonces. El cine canario -si tal cosa realmente existiera- ha tenido sueños de industrializarse desde los años del pionero José González Rivero (años 20 y 30 del siglo xx) ${ }^{6}$, ha contado con momentos de gran flaqueza, como fueron los años de la dictadura franquista, y tiempos de enorme ebullición, representados por el movimiento amateur de los años 60 y 70, la aparición del colectivo Yaiza Borges (1978-1987) y la eclosión que el digital supuso desde principios del nuevo milenio ${ }^{7}$.

Así pues, otra de las realidades más destacadas de la historia del cine en Canarias ha sido su condición de plató natural de rodajes. Es conveniente recordar

${ }^{2}$ Carnero Hernández, A. \& Pérez-Alcalde Zárate, J.A. (2011): El cine en Canarias (Una revisión crítica). Madrid: $\mathrm{T} \& \mathrm{~B}$ Editores.

${ }^{3}$ Filmoteca Canaria (2004): Yaiza Borges: aventura y utopía. Islas Canarias.

${ }^{4}$ Pérez-Alcalde Zárate, J.A. (2005): Los cine-clubes Universitario y Náutico [1953-1969]. Filmoteca Canaria.

${ }^{5}$ La historiadora Dolores Cabrera Déniz sostiene que el francés Vincent Billard viajó en 1896 a la capital de Santa Cruz de Tenerife para rodar Mujeres Isleñas de Tenerife Abasteciendo Carbón a la Escuadra dentro de las piezas de producción de los Lumière (Cabrera Déniz, 1999).

${ }^{6}$ José González Rivero es considerado como el padre del cine canario por su enorme producción entre 1922 y 1933, así como las diferentes actividades relacionadas con el sector que llevó a cabo. Es el autor del primer largometraje de ficción de las Islas, El ladrón de los guantes blancos (1926), y la primera persona que intentó desarrollar una verdadera industria cinematográfica en el Archipiélago. (Gabriel Martín y Fernández Arozena, 1997).

${ }^{7}$ En referencia a la eclosión de nuevas producciones en el territorio insular tras la llegada del digital es recomendable la lectura del artículo publicado por Jairo López y Josep M.Vilageliu en la Revista de Historia y Estética Audiovisual LATENTE, El cortometraje en Canarias durante la primera década del siglo XXI (López y M. Vilageliu, 2009), y el texto resultante de una investigación sobre el documental canario realizada por quien suscribe estas palabras con el título El documental canario en la era digital (Alegre Paiz, 2016), y que forma parte de un trabajo final de grado de Comunicación Audiovisual en la Universidad Carlos III de Madrid. 
películas como la coproducción hispano-italiana Tirma (Paolo Moffa, 1954) o la superproducción Moby Dick (John Huston, 1956), que contaba con Gregory Peck como estrella de cartel. Esta realidad llega hasta nuestros días, cuando los incentivos fiscales han traído a las diferentes islas rodajes internacionales tan sonados como las dos entregas de Furia de Titanes (Louis Leterrier, 2010) e Ira de Titanes (Jonathan Liebesman, 2012), A todo gas 6 (Justin Lin, 2013), Jason Bourne (Paul Greengrass, 2016) o Aliados (Robert Zemeckis, 2016); además de algunos títulos nacionales como Palmeras en la nieve (Fernando González Molina, 2015), Nadie quiere la noche (Isabel Coixet, 2015) o Los últimos de Filipinas (Salvador Calvo, 2016).

Sin embargo, pese a que la actividad audiovisual que se desarrolla en las Islas es notable, no es así su relación con la sociedad isleńa, que desconoce la historia y la actualidad del cine canario, y tampoco fecunda las salas repartidas por el territorio insular para acercarse a las producciones nacionales y extranjeras. No obstante, la llegada de algunos servicios online de alquiler bajo demanda, como los que ofrecen en la actualidad plataformas como Filmin, Wuaki, Movistar, Netflix o Amazon Prime Now, ha permitido a un gran número de espectadores consumir grandes producciones cinematográficas y televisivas desde el televisor de casa, el ordenador portátil o en los casos más detestables, desde una tablet o un smartphone. El acceso a estos catálogos online está ejerciendo una fuerte colonización del imaginario audiovisual colectivo, imponiendo una serie de productos que normalmente no son cuestionados por el espectador, al no poseer una educación visual y mediática que le permita ser crítico frente a tales producciones.

Al mismo tiempo, los déficits de formación audiovisual en el Archipiélago están dificultando el desarrollo de una nueva y fuerte industria audiovisual en las Islas que sea capaz de llamar la atención de los espectadores locales y foráneos, así como poder aprovecharse de los beneficios fiscales, a los que actualmente solo acceden producciones llegadas desde el exterior. Esta cuestión es una de las causas por las que la cinematografía canaria no ha logrado, salvo en conocidas excepciones, proyectarse fuera del territorio insular y alcanzar la madurez necesaria como para conformar una industria competente a los niveles de otras autonomías nacionales como la catalana, la vasca, la gallega o la andaluza. Cabe preguntarse entonces si una mejora en la educación audiovisual y mediática que recibe la población canaria podría combatir contra algunos de estos déficits culturales que acompañan a la sociedad insular desde los tiempos del cine mudo.

\subsection{El Audiovisual DENTRO Y FUERA DE LAS AUlas CANARIAS: ANTECEDENTES TEÓRICOS}

El mundo del audiovisual ha sido un tema de enorme interés en la comunidad educativa desde la aparición del cine a finales del siglo xIx. En Francia, cuna y potencia del cine europeo, su uso en la escuela se remonta hasta el año 1898 cuando el Dr. Doyen rodaba y proyectaba películas para sus alumnos, y en 1912, la suma 
de iniciativas individuales de esta índole llevó al Ministerio de Agricultura del país galo a introducir el cine con fines de formación profesional ${ }^{8}$.

Estos hechos han estado presentes en nuestro país, donde a lo largo de los años 70, 80 y 90 se recoge una enorme cantidad de textos relacionados con el cine y la escuela. Es habitual encontrar material didáctico para desarrollar estas enseńanzas, o incluso algunos artículos que se han aproximado teóricamente a esta cuestión, como las ideas expuestas por Alain Bergala en La Hipótesis del Cine. Pequeño tratado sobre la transmisión del cine en la escuela y fuera de ella o las publicaciones de Albas Ambròs y Ramon Breu ${ }^{10}$ que han contribuido a ofrecer una guía actualizada al profesor de hoy.

Sin embargo, en la labor de documentación de este proyecto de investigación apenas se ha encontrado literatura relacionada directamente con este hecho, el de la enseñanza del audiovisual y la realidad canaria. No obstante, se han conseguido encontrar algunos textos que han ofrecido valiosas aportaciones para realizar una aproximación al tema en cuestión, y para poder plantear nuevas preguntas a las que se ha intentado dar respuesta a lo largo del desarrollo de este trabajo. De ello lo más fundamental se recoge a continuación.

\subsubsection{El cine en la escuela y fuera de ella: los cineclubes}

Es habitual relacionar el proceso de enseñanza-aprendizaje con el espacio de la escuela. El pupitre y la pizarra siguen representando icónicamente a la escuela, y aunque en nuestro vocabulario popular manejamos conceptos como la «universidad de la vida» o «la escuela de la calle», lo cierto es que entendemos por educación aquello que se imparte en un aula, y, por lo general, de manera formal y reglada.

Sin embargo, como veremos a lo largo de estas líneas, la enseñanza del cine o el audiovisual en Canarias tiene varios capítulos escritos fuera de los muros canónicos de la escuela tradicional. En este sentido, la actividad desarrollada en los cineclubes fue toda una referencia a partir de 1954, año en el que se funda el Cine Club Universitario de Las Palmas ${ }^{11}$ y el Cine Club Universitario de Tenerife.

En Los cine-clubes Universitario y Náutico [1953-1969], José Antonio Pérez-Alcalde Zárate comparte con el lector su relación y memoria con respecto a la actividad de estos dos cineclubes tinerfeños. Si bien es cierto que no fueron los únicos que existieron en la Isla, y mucho menos en el Archipiélago, el contenido

${ }^{8}$ En un artículo publicado por Jean-Claude Séguin en la revista Comunicar en 2007 se hace referencia al recorrido histórico que las enseñanzas de cine han tenido en Francia. (Séguin 2007, p. 22).

9 Bergala, A. (2007): La Hipótesis del Cine. Pequeño tratado sobre la transmisión del cine en la escuela y fuera de ella. Barcelona, Laertes.

${ }_{10}$ Se trata de los textos 10 ideas clave. Educar en medios de comunicación. La educación mediática (Ambròs y Breu 2011) y Cine y educación. El cine en el aula de primaria y secundaria (Ambrós y Breu, 2007).

${ }^{11}$ Carnero Hernández y Pérez-Alcalde Zárate, 2011, p. 141. 
de este texto da cuenta de la función didáctica que podía llegar a tener este tipo de actividades en plena etapa franquista.

En dicho texto Pérez-Alcalde Zárate recuerda la definición de cineclub que fue aprobada en el I Congreso Español de Cine-Clubs, celebrado en Madrid en abril de 1952 y que reproduzco íntegramente a continuación:

Un Cine-Club es una agrupación minoritaria con carácter privado, dirigida al conocimiento y estudio de aquellos valores estéticos, técnicos y sociales del cinematógrafo.

A) Es una agrupación minoritaria porque la orientación fundamental que persigue es presentar a sus asociados aquellas películas que, por su significación independiente, no pueden ser gustadas por un público sin preparación.

B) El Cine-Club está obligado a resaltar aquellos valores cinematográficos o filmológicos que pasarían inadvertidos en una proyección comercial.

C) Porque, dado el carácter minoritario del Cine-Club, coloca al cine en su exacta dimensión estética y técnica, que no podría llevar a cabo en una sesión corriente.

D) El Cine-Club, aparte de esas sesiones organizadas con películas raras, solamente para iniciados, estudia aquellos films que marcaron alguna fecha en la historia del cinema, o bien aquellas películas representativas de un estilo, trayectoria o escuela, dentro de unas directrices preestablecidas por sus organizaciones.

E) El Cine-Club pretende el estudio del cinema mediante una rigurosa selección de sus obras fundamentales para su exacta valoración estética y social ${ }^{12}$.

Como vemos, en la definición dada existe un marcado carácter didáctico en los objetivos y definiciones de la actividad del cineclub. Este hecho no fue diferente en el caso de los citados cineclubes. De hecho, en el caso de la inauguración del Cine Club Universitario de Tenerife, celebrada el domingo 21 de noviembre de 1954, se podía leer en un folleto que fue repartido lo siguiente:

... Todos unidos vamos a la realización de un cine-club depurador de las esencias cinematográficas. Nuestra tarea se centrará fundamentalmente en el estudio de los auténticos valores del cine y su propagación, con la idea de llenar ese vacío de cultura cinematográfica, que existe en la masa del público, y que impide que el cine-arte llegue a identificarse con el cine-industria. A la larga, y conseguido nuestro común objetivo, creemos que, por imperativo de un público apto intelectualmente para gustar las bellezas de un cine auténtico, esta comunión llegará a realizarse. El camino no es largo, pero unidos confiamos cubrirlo ${ }^{13}$.

No obstante, pese a que la actividad fue seguida por un número amplio de socios -en el caso del Cine Club Náutico llegaron a tener casi seiscientos-, en la práctica ambas experiencias se limitaban, formalmente, a la exhibición de las

12 Pérez-Alcalde Zárate (2005), pp. 9-10.

13 Ibidem, p. 16. 
películas y el reparto de programas donde se incluía la sinopsis, la ficha técnico-artística y comentarios sobre alguna figura relevante. La razón de esta limitación en el acercamiento didáctico responde al poco éxito que tenían las charlas y conferencias posteriores, que, pese a contar con reconocidas figuras de la cultura del momento como fueron José Arozena, Carlos Pinto o Domingo Pérez-Minik, se eliminaron por el poco interés que demostraba el público por las mismas ${ }^{14}$.

Así y todo, la actividad de los cineclubes fue notable en el Archipiélago, desarrollándose incluso del 3 al 9 de mayo de 1954, en el caso del Universitario de Las Palmas, y del 10 al 16 de mayo de 1955 en el caso del Universitario de Tenerife, las Primeras Semanas de Estudio y Proyección del Cine Internacional, que tenían por objeto proyectar una relación de grandes películas del momento. Sin embargo, al menos en el caso de la experiencia en Tenerife, el evento fue un fracaso debido a la sustitución de muchos de los títulos previstos ${ }^{15}$. Pese a tal fracaso, hay que reconocer la labor que los cineclubes desarrollaron en las Islas con el fin de acercar el cine a la población insular, desarrollando, seguramente, una cinefilia en muchas de las personas que ocupaban los espacios de proyección. Tal experiencia se repite hoy en algunos puntos del Archipiélago, como en Tenerife, donde desde hace algunos años se desarrolla la iniciativa Charlas de Cine en los Multicines Tenerife.

\subsubsection{Los objetivos didácticos de Yaiza Borges}

El amateurismo cinematográfico en Canarias fue especialmente relevante a partir de la década de los 60, y en especial en los 70, cuando la accesibilidad a cámaras de $8 \mathrm{~mm}$ y Super- $8 \mathrm{~mm}$ permitió a un gran grupo de cinéfilos aficionados desarrollar sus propias creaciones. A partir de este fenómeno surgirían varios certámenes y concursos en las Islas que incentivaban, aún más, el auge de la producción. Sin embargo, si hay que destacar un hecho especialmente, este fue la creación de agrupaciones y asociaciones durante los 70 que acompañaba a la consolidación de esta realidad.

El 10 de enero de 1974 se constituyó la Agrupación Tinerfeña de Cine Amateur (ATCA), vinculada al Círculo de Bellas Artes de Santa Cruz de Tenerife, que tendría como presidente y vicepresidente a Teodoro Ríos y Roberto Rodríguez respectivamente. Desde la aparición de ATCA se desarrollaron numerosas proyecciones que eran acompañadas de debates tras la proyección, y en los que la discusión estaba presente (para lo bueno y para lo malo). Tras la experiencia de ATCA, en 1976 será ACIC (Asociación Canaria de Cine Independiente) la que toma las riendas, organizando ciclos de cine donde se mostraba de manera crítica la realidad oculta de una Canarias pobre.

A partir de entonces se va haciendo cada vez más fuerte el diálogo interno referido a la cuestión del cine canario, y, tal y como indica M. ${ }^{a}$ Jesús Sanabria Mesa, en

14 Ibidem, p. 34.
15 Ibidem, p. 20. 
septiembre de 1977 «se constituye la Federación Canaria de Cine no Profesional cuyo objetivo es sentar las bases para un cine canario, la creación de una infraestructura que posibilite el impulso del cine canario ${ }^{16}$. En este sentido, en el primer boletín que publicaron anunciaron, tal y como recuerda Sanabria Mesa, «la organización de cursillos prácticos y teóricos de historia del cine, lenguaje y didáctica para maestros». ${ }^{17}$

Este hecho marca un cambio en la relación entre el cine y la educación formal en Canarias. Sin embargo, el contenido de este boletín no se llevaría a la práctica hasta que sus ideas fueran retomadas y reformuladas por el Colectivo Yaiza Borges.

A finales de los 70, más concretamente en 1978, surge Yaiza Borges de las cenizas de ACIC y en plena efervescencia de cambios sociales y culturales con la transición democrática. Desde su aparición pública el 25 de octubre de 1979, cuando firman la cinta Anabel (Off-Side) en la IV Muestra de Cine Canario convocada aquel año por la Caja de Ahorros de Tenerife (cita que concede el primer premio a dicha película), el colectivo emprende una serie de actividades que presagian lo que será su futuro más inmediato y, más concretamente, sus señas de identidad fundacionales. Tal y como recuerda José A. Guerra, "el Colectivo organizó (en los dos últimos meses de la controvertida y marchita década de los setenta) una charla-coloquio sobre iniciación cinematográfica en las jornadas de animación cultural celebradas en el Cercado del Marqués, para la Delegación de Cultura, un cursillo de iniciación cinematográfica (teórico-práctico) en la Agrupación Cultural Telefónica y una proyección de films de diversas miembros del Colectivo en un bar de La Laguna» ${ }^{18}$.

Esta motivación didáctica marcó, de manera más o menos explícita, gran parte del recorrido de Yaiza Borges, estando presente dentro del manifiesto teórico que publicaron en el n. ${ }^{\circ} 0$ de su revista Barrido el 25 de enero de 1980. Según recuerda José A. Guerra, entre los contenidos de ese manifiesto se señalaban varias ideas encaminadas a reforzar la docencia audiovisual y cinematográfica de las Islas, con objetivos profesionales como la creación de una escuela de cine, la exigencia institucional de incorporar el cine como asignatura en todos los niveles de enseñanza; quedando reflejado este interés en la comisión de Área Didáctica conducida por Josep M. Vilageliu, que, junto con la comisión de Producción y Distribución y la comisión de Documentación y Publicación, conformarían desde un primer momento la organización del Colectivo ${ }^{19}$.

La actividad de la Comisión Didáctica al parecer estuvo supeditada a los encargos que recibía Yaiza Borges por parte de instituciones políticos o culturales para impartir los cursillos ${ }^{20}$. Aunque el número de cursos que recoge el texto de Yaiza Borges: aventura y utopía no es muy elevado, lo cierto es que todo parece apuntar que la documentación con la que se realizó esta publicación puede encontrarse

16 Morales Quintero, S. \& Modolell Koppel, A. (1997): Un siglo de producción de cine en Canarias (1987/1997). Las Palmas de Gran Canaria: Cabildo Insular de Gran Canaria, p. 69.

17 Idem.

${ }^{18}$ Filmoteca Canaria (2004): Yaiza Borges: aventura y utopía. Islas Canarias, p. 60.

19 Ibidem, p. 63.

${ }^{20}$ Ibidem, p. 66. 
incompleta, por el desvío de documentación y el daño que el tiempo produce en la memoria de los protagonistas de esta historia. Sin embargo, es de especial relevancia el interés que el Colectivo mostraba en esta área, siendo pioneros en la reivindicación educativa de ofrecer formación sobre un medio de comunicación en las aulas de las entonces EGB, BUP, FP y la sección de estudios especiales de la Universidad, ante una realidad institucional en la que el Ministerio de Educación Español no reconocía dicha disciplina y mantenía lo expuesto en la Ley General de Educación de 1970.

En cualquier caso, lo que a continuación se expone es un cuadro con la relación de cursos documentados que ofertaron los miembros del Colectivo desde el verano de 1978 (antes de su formación oficial) y hasta 1987, año en el que, por desgracia, Yaiza Borges desaparece, aunque no su espíritu y la actividad de algunos de sus componentes, que cuarenta años después siguen a primera línea de la actividad cinematográfica insular.

\begin{tabular}{|c|c|c|c|}
\hline \multicolumn{4}{|c|}{ RELACIÓN DE CURSILLOS IMPARTIDOS POR YAIZA BORGES (1978-1987) } \\
\hline AÑo & Cursos docentes & Otros cursos & TOTAL \\
\hline 1978 & 0 & 1 & 1 \\
\hline 1979 & 0 & 2 & 2 \\
\hline 1980 & 2 & 1 & 3 \\
\hline 1981 & 0 & 1 & 1 \\
\hline 1982 & 0 & 0 & 0 \\
\hline 1983 & 0 & 3 & 3 \\
\hline 1984 & 1 & 0 & 1 \\
\hline 1985 & 0 & 0 & 0 \\
\hline 1986 & 2 & 0 & 2 \\
\hline 1987 & 0 & 0 & 0 \\
\hline Total & 5 & 8 & 13 \\
\hline
\end{tabular}

Fuente de elaboración propia. La tabla se ha realizado con los datos recogidos en Yaiza Borges: aventura y utopia. El manifiesto de algunos entrevistados durante este proyecto sugiere que el número de cursillos fue superior.

Como se aprecia en la tabla, en efecto, el número de cursillos impartidos por Yaiza Borges durante su periodo de actividad no fue especialmente elevado, pero sí relevante por la significación que tuvieron. Es conveniente aclarar que, si bien es cierto que Josep M. Vilageliu estuvo presente en prácticamente todos estos cursos, también se contó con el apoyo y presencia de Juan Antonio Castańo y el profesor de Pedagodía de la Universidad de La Laguna Javier Marrero.

No obstante, paralelamente debería considerarse, una vez más, la motivación didáctica de los cineclubes y, en este caso concreto, del fundado por Yaiza Borges, que arrancaría su actividad el 6 de marzo de 1980. En los estatutos enviados a Madrid el 5 de diciembre de 1979, a la Dirección General de Cinematografía, para la gestión y tramitación del cineclub incluía en el primero de sus veintitrés artículos el siguiente objetivo: 
El fomento de la educación cinematográfica, mediante sesiones privadas de filmes, coloquios, cursillos y conferencias destinadas únicamente a sus socios ${ }^{21}$.

Por último, sería injusto no mencionar algunas acciones fallidas de Yaiza Borges en su intento de fomentar las enseñanzas cinematográficas en la educación formal, así como hacer alusión a los proyectos que continuaron tras la disolución del Colectivo en 1987.

En cuanto a las iniciativas fallidas, habría que destacar las siguientes ${ }^{22}$ :

- En 1979/1980 se presenta al Cabildo un proyecto para montar una Escuela de Cine, introducir la cinematografía en EGB y BUP y crear un taller de cine e infraestructura. Nunca recibieron respuesta.

- En 1981 se propuso al Ayuntamiento de Santa Cruz de Tenerife crear una Escuela Municipal de Cine. Tampoco recibieron respuesta.

- Se propone en 1983 al Ayuntamiento de La Laguna y el Gobierno autónomo un proyecto de cine en institutos con formación de profesores. Fue parcialmente aceptado.

- Se propone al Ayuntamiento de Santa Cruz de Tenerife y al Gobierno autónomo en 1983 un Festival de Cine Lúdico, con Berlanga como organizador y promotor. El proyecto es rechazado.

- En septiembre de 1984 se inician los sábados por la mañana proyecciones para institutos en el Yaiza Borges, pero el proyecto no tiene continuidad.

Antes de mencionar la actividad desarrollada después de 1987, es justo destacar la creación de un material didáctico desarrollado por Yaiza Borges bajo la petición de la Consejería de Educación de la Comunidad Autónoma, que servía a los profesores para llevar las enseñanzas del cine a las aulas. Esta Guía Didáctica del Lenguaje de la Imagen era acompañada por un vídeo didáctico de tres horas (dividido en dos VHS), en el que se presentaban ejemplos de la teoría presentada. Complementando finalmente este material, en mayo de 1986 se realizaron dos cursillos de tres días (uno en Las Palmas, y el otro en Santa Cruz de Tenerife), destinados a profesores interesados en impartir la asignatura creada para tales contenidos. Sin embargo, en palabras de José A. Guerra, «está última experiencia ha demostrado una vez más las insuficiencia temporal de tales empeños pedagógicos»"23.

Tras la desaparición del Cinematógrafo de Yaiza Borges en 1986 y la disolución del Colectivo, el espíritu que embarcó a muchos de sus miembros resistió y se mantuvo durante años, llegando incluso hasta el tiempo actual. Entre los cineastas más activos se encuentra Josep M. Vilageliu, que, además de continuar con una producción incansable de películas, mantuvo su relación con las ofertas de la

\footnotetext{
${ }^{21}$ Ibidem, p. 94.

22 Ibidem, pp. 288-294.

23 Ibidem, p. 230.
} 
didáctica cinematográfica, pero también de otros protagonistas como Juan Antonio Castaño, Luis Sánchez-Gijón, Jaime Ramos, Fernando G. Martín o Alberto Guerra, que participaron en cursos de formación para desempleados del INEM, en cursos para profesorados y en talleres técnicos.

Este tipo de cursillos se han mantenido hasta nuestros días, también potenciados por otras instituciones, y personas privadas. Sin embargo, es de acierto dedicar el siguiente capítulo a una de las experiencias más importantes desarrolladas en los últimos veinte años: hablo pues de Educar la Mirada.

\subsubsection{Educar la Mirada (2002-2008): el cine como actividad extracurricular}

En plena ebullición de la última horneada de cineastas canarios, a principios del presente siglo xxi, Josep M. Vilageliu ideó Educar la Mirada, un proyecto didáctico y cinematográfico que llevó a unos 60000 alumnos (solo en Tenerife y Gran Canaria) a las salas durante los cursos escolares comprendidos entre el 2002/2003 y el 2007/2008. Sin duda, una de las iniciativas más exitosas y normalizadas fuera del currículo escolar, en lo que a la didáctica cinematográfica se refiere. El objetivo último de este proyecto era el de acercar al alumnado el lenguaje audiovisual y cinematográfico para que pudieran comprender y valorar los textos cinematográficos. Es decir, no se trataba tanto de enseñar cine como de saber ver cine y leer cine.

No es casual que precisamente sobre Educar la Mirada se hayan realizado, hasta el momento, dos trabajos que han analizado esta iniciativa apoyada por las instituciones públicas durante sus años de ejecución. Si bien el trabajo final de máster de Gabriel Trenzado Quintero, Educar la Mirada: análisis de un proyecto ${ }^{24}$, ofrece enorme información sobre esta cuestión, lo cierto es que gran parte de la información contenida en sus páginas ya se encuentra descrita por el mismísimo Josep M. Vilageliu en El cine en Canarias (una revisión crítica), en un artículo titulado Educar la Mirada y otras experiencias pedagógicas ${ }^{25}$. Consultadas una y otra fuente de forma indistinta -no se encuentran contradicciones entre las mismas-, lo que a continuación se expone es, a grandes rasgos, lo que definió esta iniciativa.

Para entender el éxito y el apoyo institucional que recibió Educar la Mirada habría que prestar atención, tal y como afirma Trenzado Quintero, «al contexto de efervescencia cultural que se respiraba en los círculos cinematográficos ${ }^{26}$. Concretamente, a principios del presente siglo, la actividad de Filmoteca Canaria (creada en 1984), el surgimiento del Festival Internacional de Cine de Las Palmas de Gran Canaria y el aumento de la variedad en la exhibición (salas que proyectan películas en versión original, ciclos de cine...) marcaron la fiebre del audiovisual de aquellos

${ }_{24}$ Trenzado Quintero, G. (2016): Educar la Mirada: análisis de un proyecto. Trabajo final de máster de Cultura Audiovisual y Literatura. Universidad de Las Palmas de Gran Canaria.

${ }_{25}$ Carnero Hernández, A. \& Pérez-Alcalde Zárate, J.A. (2011): El cine en Canarias (Una revisión crítica). Madrid: T\&B Editores, pp. 281-290.

26 Trenzado Quintero (2016), p. 26. 
años en los que, no debemos olvidar, la cinematografía de las Islas experimenta un boom con la llegada del digital.

Precisamente en la esfera de exhibicionistas se encuentra el germen de lo que fue Educar la Mirada. Dentro del circuito de salas que proyectaban películas en versión original y en $35 \mathrm{~mm}$ en las Islas, el Multicines Aguere (hoy Espacio Cultural Aguere), ubicado en la calle Herradores de La Laguna (Tenerife), tenía una sala, bautizada como Sala Atenea, en la que se realizaban sesiones de cinefórum a partir de septiembre de 2001. Ese mismo año, según recuerda Josep M. Vilageliu ${ }^{27}$, el Centro de Profesores de La Laguna organizó un curso de Didáctica del Cine dirigido a docentes de la ESO. Aprovechando esta iniciativa se organizaron, en horario lectivo, proyecciones a más de 400 alumnos de secundaria de distintos centros de la Isla.

La experiencia de cinefórum llevada a cabo con estos alumnos y la película Kandahar, de Mohsen Makhmalbaf, resultó enormemente gratificante. Esto incitó a la directora del Centro de Profesores de La Laguna, Natalia Álvarez, a proponer la extensión de esta actividad por la red de centros de educativos por medio de la Consejería de Educación. La propuesta fue acogida con cierto entusiasmo (según narra la memoria de los protagonistas) y permitió que la Dirección General de Promoción Educativa la incluyera en el Plan Canario de Actividades Extraescolares, sumándose poco después Filmoteca Canaria, que cedería sus dos espacios de proyección en Tenerife (el Cine Víctor) y en Gran Canaria (Multicines Monopol).

El proyecto se puso en marcha en el curso 2002/2003 y se dirigía a los alumnos de secundaria de los centros participantes. La actividad se realizaba preferentemente en las salas de proyección de Filmoteca, o en salas alternativas o centros culturales que facilitaban sus espacios. Por lo general, las películas se proyectaban en $35 \mathrm{~mm}$ y en versión original, salvo, como es lógico, en los casos en que las proyecciones debían realizarse forzosamente en las instalaciones del centro escolar, donde se recurría al DVD.

Si bien es cierto que estas actividades no ofrecían una verdadera formación en materia audiovisual a los alumnos, sí permitían despertar el interés por el cine, o mejor dicho, por ese otro cine al que no tenían un fácil acceso. Por otro lado, el proyecto funcionaba como un plan lector, pero de cine, en el que se fomentaba la capacidad crítica y analítica del alumnado. Para entender mejor cuál era la ejecución práctica del proyecto, es de necesaria lectura el trabajo de Trenzado Quintero, en el que además de ofrecer una explicación teórica desde una perspectiva historicista, dedica todo un apartado a un ejemplo concreto, el de la película francesa Exils (2004), de Tony Gatlif.

En cualquier caso, y a modo de resumen -no es el objetivo de este apartado emular todo el contenido de los dos trabajos ya mencionados, sino anotar aquello que considero más relevante- habría que apuntar lo siguiente:

Durante cada curso se seleccionaban dos películas que eran objeto de ser proyectadas y visionadas en diferentes espacios por aquellos centros que lo solicitaran.

${ }^{27}$ Carnero Hernández y Pérez-Alcalde Zárate (2011), p. 284. 
Antes de acudir a las proyecciones se les facilitaba a los profesores un material didáctico que debían trabajar previamente con los alumnos en el aula. Ya en la jornada de proyección, los monitores (normalmente jóvenes estudiantes universitarios sin experiencia docente, pero con un enorme interés por el cine) realizaban una breve introducción (15 minutos) en la que se presentaba la película y se ofrecían pistas sobre aquello a lo que tenían que prestar mayor atención. Luego, tras el visionado, se realizaba un cinefórum, que era más o menos exitoso según hubiera sido el trabajo previo que el profesorado había realizado en el aula ${ }^{28}$. Ya en las aulas, al profesorado se le servía un material que le permitía continuar trabajando con sus alumnos tras el debate iniciado en las salas.

También, pero con mayores problemas en la continuidad, se realizaban cinecharlas en los centros escolares en coordinación con los Centros de Profesorado. Durante el tercer trimestre escolar se realizaban una especie de clases de introducción al lenguaje audiovisual a través de la proyección de cortes de películas en DVD. Para ello se realizaron DVD didácticos sobre distintos temas ${ }^{29}$. Sin embargo, los problemas técnicos de dotación de algunos centros, así como la logística de coordinación y desplazamiento de los monitores, restaron éxito a esta iniciativa.

De esta forma, y siguiendo por lo general este guion, Educar la Mirada mostró a unos 60000 alumnos de todo el Archipiélago otra manera de interactuar con el cine y, por ende, con el lenguaje audiovisual. Durante los cinco cursos que duró esta iniciativa -la crisis económica no permitió su continuidad en el curso 2008/2009-, el boom del cine canario no estuvo presente únicamente en festivales locales, o en el panorama de producción (ligado fundamentalmente a la realización de documentales y cortos de ficción), sino que se experimentó en las aulas de aquellos centros que, de una u otra manera, acercaron el séptimo arte a sus alumnos.

\subsubsection{Otras claves de la enseñanza audiovisual en la universidad, la formación profesional y la educación obligatoria}

Antes de concluir este apartado de antecedentes, en el que se ha pretendido dar cuenta de los principales textos referidos al objeto de estudio de este proyecto, es oportuno citar aquello que se ha dicho acerca de la educación audiovisual en las

${ }^{28}$ En referencia al éxito del coloquio tras la proyección, Josep M. Vilageliu afirma que «... enseguida se comprobó que la calidad de los coloquios dependía mucho de los profesores, de si los alumnos estaban o no acostumbrados a debatir en clase o de cómo se habían preparado previamente las sesiones. En muchos casos, el desconocimiento de los alumnos respecto al contexto político y social del tema tratado en la película era apabullante, como en los casos del conflicto de los Balcanes, el Holocausto, la situación de palestinos y judíos, etc., que impedía centrarse en la película en sí y amenazaba en convertir las sesiones en una clase Historia». Ibidem, p. 283.

${ }^{29}$ Concretamente eran: Un recorrido desde la narrativa clásica hasta el cine de la modernidad; Una reflexión sobre la puesta en escena a través del análisis de secuencias, y Relaciones y contaminaciones entre documental y ficción en el cine contemporáneo. Idem. 
enseñanzas de formación profesional (FP), la universidad en Canarias y proyectos ligados a la educación obligatoria en primaria y secundaria. Si bien es cierto que la bibliografía referida a estas cuestiones es muy limitada; de hecho, todas las referencias que se apuntan a continuación han sido encontradas en un mismo texto ya citado con anterioridad, el imprescindible El Cine en Canarias (una revisión crítica).

En el capítulo 21, firmado por Josep M. Vilageliu, Educar la Mirada y otras experiencias pedagógicas, del que ya hemos señalado información referente al proyecto de Educar la Mirada ${ }^{30}$, se dedican las últimas páginas al proyecto Despertares. Este proyecto de animación a la lectura de la imagen cinematográfica estaba dirigido al alumnado de primaria, secundaria y bachillerato de centros educativos, tanto públicos como privados, y fue ejecutado durante los años 2005 y $2008^{31}$.

Con el objetivo de ofrecer un conocimiento referido a la evolución del cine y su consideración artística, el proyecto, que tenía como sede central la sala de proyecciones de CajaCanarias en Santa Cruz de Tenerife, realizaba sesiones de una hora de duración en las que se proyectaban numerosos fragmentos fílmicos que compartían una misma unidad temática. Las panorámicas -así se denominaban estas sesiones- se adaptaban a las edades de los alumnos y a la petición de los docentes, siendo algunas de ellas: Historia del cine: el cine de los pioneros; Ciencia ficción: más allá de las estrellas; La fantasía en los anime japoneses, o Comidas de cine: salud y alimentación a través del cine.

Paralelamente, bajo pedido de los centros, también se desarrollaban las conocidas como primeras sesiones, que consistían en realizar proyecciones con presentación y coloquio, siguiendo la fórmula de los cinefórums. Hay que destacar que en un primer momento se pretendía que estas sesiones se realizaran los lunes por la tarde en CajaCanarias, aprovechando los ciclos de cine que se celebraban entonces; sin embargo, el bajo índice de asistencia por parte de alumnos provocó el cambio a ese sistema bajo demanda. Finalmente, hay que señalar que, al igual que ocurría con las panorámicas, a los centros se les enviaba material didáctico en el que se incluían las fichas de las películas proyectadas.

Como vemos, durante la década pasada, parte del alumnado canario tuvo la oportunidad de disfrutar de una aproximación distinta hacia el cine. Esto, sin duda, despertaría el interés de más de uno, y quién sabe, en el mejor de los casos dicho interés sería acompañado por una cinefilia incipiente. Sin embargo, si alguno de estos (u otros) alumnos deseaban (o desean) realizar sus estudios medios o superiores en relación con el audiovisual, la realidad les presenta pocas ofertas formativas en las Islas. En resumen, solo pueden acceder a los cursos técnicos ofertados en tres centros de FP (dos en Tenerife y uno en Gran Canaria), y en el caso de la universidad pública, la ausencia de un grado/licenciatura de Comunicación Audiovisual obliga a escapar del Archipiélago o contentarse con algunas optativas que se encuentran en los programas de ciertas titulaciones.

${ }^{30}$ Carnero Hernández y Pérez-Alcalde Zárate (2011), pp. 281-290.

31 Ibidem, p. 287. 
Precisamente en referencia a esta pobreza formativa Rolando Díaz afirma, en el capítulo 19, Trilogía: una mirada personal al cine canario actual ${ }^{32}$, que

el asunto de la formación sostenida, reglada y sistematizada es para el audiovisual canario, un talón de Aquiles. Un asunto pendiente, una larga deuda, una tarea postergada que debilita el fortalecimiento de una posible industria local. No poseer una Escuela Oficial de Estudios Audiovisuales, así de rimbombante podría ser el nombre, es una de las carencias vitales de la Autonomía canaria en materia de educación ${ }^{33}$.

Díaz, de forma escueta, pero directa, ofrece algunas afirmaciones de interés referidas a la formación existente en el momento de publicación de sus líneas. Sobre la formación profesional señala:

Si bien es cierto que los Institutos de Formación Profesional que existen en las Islas se esfuerzan por suplir esa ausencia [se refiere a las formaciones académicas «serias»], alguna con importantes logros educativos, también es verdad que no están dotados ni diseńados para suplir un proceso formativo más complejo propio de un nivel académico universitario ${ }^{34}$.

Así pues, Díaz señala con especial atención algunas iniciativas concretas que, desde su posición, han tenido cierto éxito. La primera de ellas sería la Escuela de Actores de Canarias (EAC), que comenzó su actividad docente a finales de los noventa. Desde entonces se ha prestado especial atención al cine y la televisión con asignaturas como Interpretación Cinematográfica, que ofrecía a los estudiantes la posibilidad de, además de entender las técnicas del lenguaje del cine para la interpretación, escribir sus propios personajes en los guiones. De hecho, el éxito de la EAC se refleja además en la conversión de algunos de sus alumnos en cineastas destacados del panorama actual del cine canario, como son Jaime Falero, David Pantaleón, Domingo de Luis o Carlos de León.

Por otra parte, destaca, como no podría ser de otra manera, la función que ha ejercido desde 2008 el Laboratorio de Escritura Audiovisual de Canarias (LEAC), que fue propuesto por Andrés Koppel y coordinado junto al propio Rolando Díaz; siempre con el apoyo de Canarias Cultura en Red. Este laboratorio acompañaba al trabajo de escritura de guiones, que previamente eran seleccionados desde sus sinopsis. De esta forma se ofrecía una enseñanza específica y directa. Más tarde, en 2011, surgiría CreaDoc, vinculado al LEAC y al Festival Internacional de Cine Documental de Guía de Isora MiradasDoc, que bajo la misma premisa del LEAC trabajaría proyectos documentales canarios, por lo general documentales de creación.

\footnotetext{
32 Carnero Hernández y Pérez-Alcalde Zárate (2011), pp. 247-269.

33 Ibidem, p. 247.

34 Ibidem, p. 248.
} 
Ya por último, en lo que atañe a la formación universitaria, es de gran interés la lectura del capítulo 20, Enseñar cine, proyectar cine. La labor de la ULL en la difusión del séptimo arte, firmado por el historiador Domingo Sola Antequera. En dicho capítulo se dedican diez páginas a las distintas acciones realizadas por la Universidad de La Laguna (ULL), como han sido diversas asignaturas o la creación del Cine Club Universitario, conocido hoy como Aula de Cine.

Con respecto a la impartición de asignaturas, Sola Antequera señala al Plan 76 como hito de la aparición de la primera materia que trajo el cine a la ULL. Concretamente se trataba de la asignatura Historia del cine, que estaba integrada dentro de la licenciatura de Geografía e Historia, en la especialidad de Historia del Arte en cuarto curso ${ }^{35}$. Dicha asignatura tuvo el carácter de optativa, y se incorporaría en el mismo Plan 76 al currículo de Bellas Artes, y tiempo después al segundo ciclo de Ciencias de la Información, concretamente en el curso 1988/89, por parte del profesor Luis Fernando de Iturrate Cárdenes -único docente de la especialidad de comunicación audiovisual desde entonces-.

Sola Antequera también destaca lo siguiente:

En 1994 se aprobaría un nuevo plan de estudios a nivel estatal en el que por primera vez la Historia del Cine pasaba a convertirse en una asignatura de carácter troncal, pasando a tener 12 créditos, uno y medio más en La Laguna, desarrollándose en tres asignaturas que cronológicamente abarcan todos los contenidos de la materia. En la licenciatura además se incorporaron como asignaturas optativas: Arte y medios de comunicación, Historia del Cine Español y Teoría del Cine, además de Introducción al Lenguaje cinematográfico en tercer curso, en este caso de manera obligatoria ${ }^{36}$.

Este hecho ha provocado, según indica el autor, que en el marco de la ULL surgieran grupos de investigación dedicados a esta área, profesores especializados en la materia -como el propio Sola Antequera, quien la impartiría a partir del curso 1999/2000 como profesor asociado- y, como hecho más destacado, la aparición en 2003 de Latente. Revista de historia y estética del audiovisual. Este último hito tiene un especial interés, en cuanto que conforma un potente apoyo intelectual y académico a los estudios culturales del audiovisual en Canarias.

Finalmente, sobre el Cine Club Universitario, más tarde Aula de Cine, Sola Antequera esboza un recorrido histórico desde su origen en septiembre de 1967. Como hemos visto a lo largo de estos antecedentes, los cineclubes significaron un punto de encuentro para cinéfilos y curiosos que deseaban acercarse a un cine distinto al que se proyectaba en las principales salas comerciales. En muchas ocasiones estos cineclubes eran acompañados de coloquios tras la proyección. En el caso del Cine Club Universitario destaca que desde su origen hayan sido los alumnos universitarios quienes integraran dicha organización.

\footnotetext{
35 Ibidem, p. 271.

36 Ibidem, p. 272.
} 
El devenir del Cine Club Universitario ha estado repleto de altibajos, coincidentes en el tiempo con otros cineclubes destacados en el territorio tinerfeño, como fue el caso de las iniciativas despertadas por Yaiza Borges desde finales de los 70. Sin embargo, como carácter singular, la subscripción del Aula de Cine a la institución universitaria le ha permitido extender su marco de acción, realizando actividades como la celebración de la I Semana de Cine y Ciencia, en abril de 1992, o la realización de revistas como Plano Medio o Rosebud. Revista de Cine (1991). En la actualidad, como veremos más adelante, el Aula de Cine parece despertar tras años de escasa actividad, aunque, eso sí, sin la programación diversa y nutrida de otros periodos.

En conclusión, la literatura referida a la enseñanza del audiovisual en las Islas es bastante escasa y, además, suele atender a la memoria de sus protagonistas o, en algún caso concreto al análisis breve de algún evento de interés -como en el ya mencionado trabajo final de máster sobre Educar la Mirada-. Por otro lado, es llamativo que todos los textos encontrados hagan referencia, especialmente, a las enseñanzas o iniciativas llevadas a cabo en Tenerife. Este hecho plantea si las iniciativas didácticas en Tenerife han sido más notables en el tiempo y, por otro lado, en caso de no serlo, qué explica la ausencia de textos referidos a las acciones encaminadas en otras islas, en especial Gran Canaria. A pesar de todo, como se verá más adelante, la realidad demuestra que, por ejemplo, en Gran Canaria han tenido un gran peso formativo los cursos y talleres llevados a cabo por el centro dependiente del Cabildo, Gran Canaria Espacio Digital, y en la actualidad alberga la mayor oferta de estudios superiores relacionados con el audiovisual.

\section{LA EDUCACIÓN AUDIOVISUAL EN CANARIAS}

Para acercarnos a la realidad de la educación audiovisual en Canarias debemos entender que la misma se compone de distintos agentes que han participado, de una u otra forma desde la segunda mitad del siglo xx. En cualquier caso, esta historia se conforma de pequeños organismos con orígenes, fines y medios muy dispares que, no obstante, han dado lugar a un particular y frágil ecosistema educativo y de formación. Dicho ecosistema requiere hoy una atención especial por parte del sector audiovisual de las Islas y, por supuesto, de la Administración pública. Para entender los déficits y aciertos que nos han acompañado a lo largo de esta breve historia, debemos añadir a lo descrito con anterioridad una serie de hechos que terminan de armar lo que ha sido la educación audiovisual en Canarias.

\subsection{LAS ENSEÑANZAS ARTESANALES}

La formación en el audiovisual en Canarias no comenzó su formalización hasta los ańos 80 , cuando se empieza a integrar en los currículos escolares y aparece la especialidad de Imagen y Sonido en la formación profesional. Sin embargo, esta realidad no significa que antes de ese tiempo no existiera un interés por el 
audiovisual; de hecho, la necesidad de adquirir aprendizajes sobre cine, fotografía o radio era tan amplia que forzó a muchos profesionales y curiosos del momento a desarrollar habilidades y adquirir aprendizajes de manera «artesanal», tal y como lo define José Pestano.

Estas enseñanzas artesanales eran, de hecho, muy similares a la tradición de los gremios profesionales. Los técnicos del momento compartían su conocimiento con los aprendices, que iban adquiriendo sus habilidades del aprendizaje en práctica y por el contacto con otros "profesionales del sector»-son evidentes los déficits que tal sistema de enseñanza conllevaba-. De esta forma, y en ocasiones acompañados de cursos o algún examen que certificara las habilidades, se formaban los técnicos de radios o el personal de RTVE en las décadas previas al surgimiento de los cursos de FP. No obstante, también aparecen iniciativas privadas y públicas que vienen a reforzar y profesionalizar distintas facetas del sector audiovisual.

En conversación con José Pestano, cita por ejemplo los cursos de fotografía que imparte Luis Nóbrega en los años 70. Según Pestano, a través de su academia en Santa Cruz de Tenerife, presentaba un procedimiento «bien estructurado y con una muy buena didáctica a través de distintos cursos sobre fotografía en blanco y negro, en color...». Otro caso sería, en el ámbito radiofónico, las Escuelas del Frente de Juventudes, con la Radio Juventud de Canarias (la estación de la Cadena Azul de Radiofusión ${ }^{37}$ ), que sirve como plataforma de formación de locutores, técnicos y personal relacionados con la radio.

Todas estas iniciativas constituirían una educación técnica artesanal, exenta de un conocimiento teórico, y alejada, en un principio, de la cinematografía, por los elevados costes de los sistemas de grabación y la falta de una industria propia que impulsara la creación profesional en aquellos años. Pese a todo, el cine también encontró su particular enseñanza no formal a través de los cineclubes, que desde los años 50 llegarían a las Islas. Como vimos en los Antecedentes teóricos, los cineclubes tenían un papel protagonista a la hora de proyectar películas alternativas con respecto al circuito oficial de salas, controlado ferozmente por el sistema censor del franquismo.

Sin embargo, aunque se fomentaba el debate y fórmulas de cinefórum, lo cierto es que a la gran mayoría del público únicamente le interesaba asistir a la proyección. Al mismo tiempo, este público no estaba democratizado, porque dependía de su situación geográfica (cercanía con respecto a las ventanas de proyección) y de un conocimiento o interés previo sobre la cinematografía que le invitara a asistir a las salas. Dicho esto, y teniendo en cuenta las dificultades que tenían los cineclubes de las Islas para recibir las películas desde el territorio peninsular, sería lógico pensar que la incidencia en Canarias fue menor a la del resto del territorio español, donde significó un importante canal de exhibición.

${ }^{37}$ La actividad de Radio Juventud de Canarias se inició en 1955 y finalizó en 1978, tras la muerte de Franco y el proceso de transición democrática. Para más información al respecto, se puede consultar el trabajo de Julio Yanes Las ondas juveniles del franquismo: Radio Juventud de Canarias, 1955-1978 (Ediciones Baile del Sol, 2009). 
Ya por último, habría que destacar la labor del Colectivo Yaiza Borges. Su importancia en la enseńanza del cine bien merece un apartado propio. No obstante, se debe enunciar en esta parte la importancia que tuvieron su actividad cineclubista en los 80 y las numerosas iniciativas conducidas por el Área Didáctica que organizaba Josep M. Vilageliu. Sin duda, la aparición de Yaiza Borges supuso el puente entre las enseñanzas artesanales y las formales, en pleno proceso de transición política, con todo lo que eso suponía.

\subsection{La labor de Yaiza Borges en la educación audiovisual formal e in- FORMAL}

Durante los años 70 se produce en todo el territorio nacional una oleada de cambios. Franco fallece el 20 de noviembre de 1975, pero ya en los últimos años de su vida la sociedad comienza a reclamar una renovación política, social y cultural. Con la muerte del dictador, y la transición democrática en marcha, se produce un estallido de euforia en varias esferas de la sociedad, entre las que se encuentran, cómo no, el cine y la educación.

En este tiempo la educación formal española está reglada por La Ley 14/1970, de 4 de agosto, General de Educación y Financiamiento de la Reforma Educativa. Dicha ley organizaba todo el sistema educativo español, estableciendo y configurando las materias curriculares. Como nota informativa, habría que destacar que no existe ninguna referencia directa hacia el cine o lo audiovisual en dicha ley; por lo que curricularmente no estarían establecidas estas enseñanzas de manera formal. No obstante, en el artículo 18 se recoge lo siguiente:

Uno. Los métodos didácticos en la Educación General Básica habrán de fomentar la originalidad y creatividad de los escolares, así como el desarrollo de aptitudes y hábitos de cooperación, mediante el trabajo en equipo de Profesores y alumnos. Se utilizarán ampliamente las técnicas audiovisuales ${ }^{38}$.

Esta alusión a las «técnicas audiovisuales» marca lo que será la corriente predominante desde entonces en la aplicación del audiovisual en las aulas; esto es: el uso de los medios audiovisuales como herramientas educativas. Tal consideración del audiovisual, no solo resta importancia teórica y/o científica a los posibles conocimientos vinculados a dicha corriente cultural y artística, sino que reduce su protagonismo a un papel secundario, por detrás del currículo de las materias formales.

No obstante, este contexto legislativo choca de frente contra el verdadero contexto social, cultural y artístico que se vive en España en ese momento. Durante los 70 se experimenta una verdadera fiebre de eclosión cultural que en el cine tendrá

${ }^{38}$ Ley 14/1970, de 4 de agosto, General de Educación y Financiamiento de la Reforma Educativa (BOE núm. 187, de 6 de agosto de 1970, p. 12529). 
su reflejo más mediático en lo que se conoce popularmente como «el destape». Dicho proceso se ve acompañado también de un cine social y político que nace a espaldas de la censura y se reivindica en la Transición. Todo esto, sin olvidar el papel cada vez más protagonista que juega la televisión en los hogares españoles. Este contexto produce una necesidad en la sociedad por entender la imagen y ser capaces de interactuar de manera crítica y "democrática» con los mensajes y contenidos que crean y comparten los medios audiovisuales y mediáticos.

Será precisamente esta necesidad la que lleve a asociaciones de cineastas, pedagogos y docentes a reclamar un aumento del protagonismo del cine en las aulas. En el caso de Canarias, como ya vimos, las reclamaciones de potenciar una didáctica del cine estuvieron presentes en los objetivos de la «Federación Canaria de Cine no Profesional», organizada en septiembre de 1977, y que serían finalmente puestos en práctica por el Colectivo Yaiza Borges.

Sin embargo, a este supuesto habría que añadirle un antecedente. Durante la III Convención de Cine Infantil en $16 \mathrm{~mm}$, celebrada en Barcelona del 20 al 25 de septiembre de 1976, se formalizaron las bases de un organismo de actuación nacional que tenía como fin potenciar la presencia de los medios de comunicación audiovisuales (MCAV) en el campo «infantil y juvenil». Lo que se venía a recoger en el documento resultante sería un listado de principios, organización y procedimientos.

De la lectura de los principios es reseñable la importancia dada al «espíritu crítico» del espectador (en este caso infantil y juvenil), así como la potencialización de las capacidades creativas y de comunicación a través de los MCAV. Así mismo, se habla de crear un Departamento de Audiovisuales en todos los centros educativos, o de la integración de los MCAV dentro de las enseńanzas regladas del sistema educativo. Todo esto estaría apoyado, desde ese momento, por distintas gestoras provinciales de Andalucía, Aragón, Asturias, Cataluña, "Centro", Galicia, País Valenciano y Murcia y País Vasco. En Canarias no tuvo éxito la idea.

No obstante, este hecho vendría a probar todo el movimiento que comienza a generarse en torno a la inclusión de lo audiovisual en la vida educativa. Al parecer, en noviembre de 1976 se redactó un documento en el que se prestaba atención a las necesidades descritas, desde Tenerife, con respecto a esta realidad. Ahí llama la atención la reclamación de «la enseñanza del cine en EGB», la «necesidad de la creación de un equipo de maestros preparados para impartir clases sobre cine a los niños» y la alusión a la Asamblea de Cineastas Independientes Canarios (ACIC).

En cualquier caso, lo más llamativo serían los objetivos expuestos, ya que estos quedarían resueltos (con mayor o menor éxito) por el Colectivo Yaiza Borges y sus integrantes años más tarde. Tales objetivos eran:

- Cursillos de preparación de maestros (en La Laguna, por zonas, etc.).

- Inclusión del cine en el programa de Magisterio, dentro de la rama de Historia (en Historia del Arte o en Medios Audiovisuales) y en la rama de Lengua (Semiología del cine, etc.).

- Confección de un texto que sirva como guía a los maestros y como base de futuras discusiones a partir de su viabilidad. 
- Creación de una filmoteca escolar para las clases prácticas y para un futuro cineclub infantil y juvenil.

Será a partir de entonces cuando, por medio de los integrantes de Yaiza Borges, o de otras iniciativas privadas, comience en el Archipiélago un movimiento dirigido a llevar el cine a la escuela. Una de las primeras referencias halladas se encuentra recogida en el periódico La Tarde, el 12 de marzo de 1977, en un artículo firmado por Josep M. Vilageliu titulado «Didáctica del cine». En el primer párrafo del mismo se puede leer lo siguiente:

Hace unos días, organizado por el I.C.E. y en el Hogar Escuela de Santa Cruz de Tenerife, tuvo lugar un cursillo sobre «Didáctica del Cine», enfocado a los maestros y alumnos de Magisterio. La finalidad del cursillo era doble: por un lado dotar a los maestros de unos conocimientos básicos sobre el fenómeno cinematográfico, para que a su vez pudiesen incluir esta materia dentro de los programas actuales de E.G.B., «aunque si hemos de esperar un actitud clara del ministerio al respecto, diría don Francisco Guzmán, licenciado en Cine y director del cursillo, no iremos a ninguna parte. Tenemos que irlo introduciendo nosotros mismos, sensibilizando a la sociedad sobre su importancia. Y eso es un proceso muy lento». Por otro lado, lo que se trató también en el cursillo es de que los maestros utilicen el cine, así como los medios audiovisuales a su alcance, en la enseñanza. Es decir, enseñar cine a los niños para desarrollar su capacidad crítica como espectadores y para que puedan expresarse mediante él, y enseñar mediante el cine ${ }^{39}$.

Este cursillo de treinta horas (ajeno a la actividad de Yaiza Borges), que Vilageliu criticó por su organización, su carácter elitista y a la parcialidad reflejada en la visión única de Francisco Guzmán, sería un ejemplo de innumerables iniciativas y cursillos que se repetirían de manera desigual, y sin atender a ninguna periodicidad concreta, durante los siguientes años, e incluso décadas, ya que en la actualidad se siguen sirviendo cursos de formación al profesorado en materia digital y/o audiovisual.

Con Yaiza Borges y su Área Didáctica se realizaron numerosos cursos para profesores desde finales de los 70 -en los Antecedentes teóricos se muestran datos al respecto-. Sin embargo, el papel que jugó este Colectivo fue, incluso, más relevante; quizá por coincidir con todo el proceso de transición democrática, o por el carácter marcadamente político que tenía Yaiza Borges. No es que el Colectivo tuviera deseos de participar activamente en la nueva esfera política incipiente, ocupando cargos de responsabilidad o conformando un partido político; sino, más bien, que sus reivindicaciones se realizaban directamente a las fuerzas políticas gobernantes en aquellos años, lo que le garantizó parte de sus éxitos (la creación de Filmoteca Canaria) y de sus fracasos (un desgaste en la organización y funcionamiento del Colectivo).

Sea como fuera, y ante la demanda de una asignatura de cine en el currículo educativo, a principios de los 80 comienzan a darse los primeros pasos hacia una

39 Vilageliu, J.: «Didáctica del cine». La Tarde, 12 de marzo de 1977, p. 17. 
regulación del audiovisual en las aulas. Dado el interés por una asignatura de cine o de medios audiovisuales, y teniendo en cuenta los pasos que se empezaban a dar en el territorio peninsular -surgen iniciativas individuales que llevan el cine a las aulas-, la Consejería de Educación se pondría en contacto con Yaiza Borges y/o el Centro de Profesores de La Laguna para crear cursillos de cine para profesores, ante la inclusión de una asignatura optativa que se impartiría en BUP sobre lenguaje cinematográfico, y que según recuerda Juan Puelles (quien la impartió durante sus dos primeros cursos) se llamaría Enseñanzas Artísticas Técnico-Profesionales.

$\mathrm{Si}$ analizamos el plan de estudios propuesto por la Ley General de Educación de $1970^{40}$, nos daremos cuenta de que en BUP existía una asignatura optativa denominada Enseñanzas y Actividades Técnico-Profesionales (EATP). Los alumnos en $2 .^{\circ}$ y $3 .^{\circ}$ de BUP debían escoger una de las optativas ofertadas dentro de esta materia, que tenía un carácter profesional (por lo que en muchas ocasiones el docente era profesor de formación profesional o procedía del mundo profesional de la especialidad ofertada). Entre las distintas materias se encontraban informática, electricidad, diseño, teatro, labores del hogar, fotografía o astronomía.

En la práctica, eran los centros los que decidían qué optativas ofertaban, teniendo en cuenta la disponibilidad de docentes y recursos hábiles para llevarlas a cabo. No obstante, debían ser aprobadas previamente por el Ministerio de Educación y Ciencia, el cual acotaba la oferta a los siguientes campos profesionales: sectores de actividades agropecuaria, industrial, comercial, náutica-pesquera, administrativa, artística y otras que se consideren adecuadas.

Es de suponer que el cine, por tanto, entraría en el campo de las enseñanzas artísticas -si bien considerar al cine como un arte era entonces más conflictivo que en la actualidad- o quizá en el campo de la industria, lo que sería aún más descabellado teniendo en cuenta la delgadez de la industria cinematográfica durante aquel tiempo. Sea como fuera, la Administración canaria impulsó y apoyó a algunos centros a ofertar la optativa de Lenguaje Cinematográfico dentro de las EATP, y para tal instancia se organizó en Tenerife un cursillo para profesores en el Instituto de La Laboral (probablemente en algún momento de 1983) conducido por Yaiza Borges. De esta forma, en el curso 1984/1985 se tiene constancia de que en el actual IES Mencey Acaymo, Juan Puelles impartiera dicha materia -sin embargo, es muy probable que también se ofertara en otros centros del Archipiélago-.

Sobre su experiencia, Juan Puelles relata que únicamente impartió esta optativa durante dos o tres cursos, continuando con ella otros compañeros. Ante la falta de equipamiento técnico, ponía en práctica los conocimientos teóricos del cine a través de ejercicios de fotonovela, que al menos durante el primer año tuvieron éxito. La materia, que se impartía durante dos horas a la semana a lo largo del curso escolar, se convirtió en un suplicio cuando ingresaban en ella alumnos no interesados

${ }^{40}$ Los artículos 23, 26, 61 y 112 de la Ley General de Educación de 1970 regulan la materia de Enseñanzas y Actividades Técnico-Profesionales (EATP). 
(probablemente los que sobraban de otras optativas de moda por aquel entonces, como informática), ya que estos entorpecían y dificultaban la experiencia práctica.

Teniendo esto en cuenta, habría que mencionar otra importante aportación de Yaiza Borges para la formalización educativa del cine en el Archipiélago. En 1985 la Consejería de Educación del Gobierno de Canarias le encargó al Colectivo la realización de un vídeo didáctico sobre cine, titulado El lenguaje del cine ${ }^{41}$.

Esta guía visual de tres horas y media de duración servía de soporte para la guía didáctica realizada por ellos mismos, la cual se empleaba en los cursillos de formación de profesorado, e incluso para su uso en el aula, ya que la Junta de Canarias distribuyó este material (compuesto por la guía y dos VHS con los vídeos didácticos) por todos los colegios e institutos donde impartía la ya citada asignatura de Cinematografía.

Pese a los errores contenidos en este material, hay que apuntar la innovación que esta iniciativa supuso en aquel momento. Recordemos que una medida similar fue llevada a cabo por Alain Bergala en 2001 a través de su "videoteca»; por lo que es plausible el esfuerzo y la dedicación que el Colectivo realizaba en aquellos años en los que el cine era, en España, y de manera más cruda en Canarias, un medio de difícil acceso, de escasa o nula industria, y un gran tabú en la escuela tradicional.

Por último, no hay que olvidar que la actividad didáctica de Yaiza Borges continuaría tras su desintegración en 1987, a través de la edición de material didáctico, o con especial incidencia mediante los cursillos de profesores o de desempleados a través de distintos talleres y cursos profesionales ofertados por el INEM. Sobre esto último habría que apuntar que ante las deudas asumidas por el Colectivo tras el cierre del Cinematógrafo, estos cursos del INEM les permitirán reducir los números en rojo. Algunos de estos cursos trataban sobre "Animación Socio-Cultural (Cine-Clubs)». La finalidad de los mismos era preparar personal competente de abordar la labor de conducción de un cineclub ante la inminente desaparición de los cines locales que ya se advertía a finales de los 80 . Por ello, se realizaba una selección entre los interesados, teniendo cierta preferencia aquellos que ya tenían experiencia.

Es innegable la finalidad didáctica que pudieron tener estos, $\mathrm{u}$ otros cursos impartidos por Yaiza Borges, o miembros del colectivo que continuaron de manera individual realizando cursos para profesores, alumnos, o incluso para escuelas de teatro. Esto sin duda incitaría a más de uno a ligar su vida profesional o cultural al cine. El espíritu didáctico y divulgativo de Yaiza Borges nunca palideció.

${ }^{41}$ Esta misma Consejería ya le había encargado a Yaiza Borges la realización de otros materiales didácticos en formato audiovisual sobre distintas cuestiones relacionadas con la cultura y naturaleza canaria. Entre los más destacados se encuentra una colección dedicada al volcanismo de las Islas. 


\subsection{LA FORMACIÓN PROFESIONAL}

Como ya se ha apuntado, en los años 80 comienza la educación audiovisual reglada en Canarias. La asignatura optativa sobre cine de la materia Enseñanza y Actividades Técnico-Profesionales llega a las Islas más de una década después de que se implante la Ley General de Educación de 1970. Del mismo modo, los cursos de formación profesional se oficializan de manera tardía en el Archipiélago, y en el caso de la rama de Imagen y Sonido habría que esperar hasta 1983 para que se incorporara a la oferta formativa de las Islas.

Por lo tanto, y recuperando la idea expuesta en el primer punto, hasta que no se inauguran los estudios de Imagen y Sonido en 1983, la única vía formativa en los campos relacionados con la creación, la producción y la realización audiovisual depende de las enseñanzas artesanales, del aprendizaje en el trabajo y de la huida hacia Madrid o Barcelona (asociadas tradicionalmente al saber y conocimiento de estas materias). Esta circunstancia, por desgracia, no ha variado en gran medida.

En cualquier caso, en el otoño de 1983 arrancan los estudios de Tecnología de imagen y sonido en el Instituto Politécnico de Formación Profesional de Santa Cruz de Tenerife (actualmente el CIFP César Manrique). Para ello se le encarga a Luis Fernando de Iturrate Cárdenes la organización e implantación de dichos estudios dentro del Área Tecnológico-Práctico de Imagen y Sonido; siendo, por tanto, el responsable de crear los primeros estudios de imagen y sonido en FP en Canarias ${ }^{42}$.

Durante ese primer año sería el único profesor en dicho centro; luego, en el curso 1984/85 llegaría otro docente e Iturrate sostendría también el cargo de Jefatura del Seminario Tecnológico-Práctico de Imagen y Sonido durante los cursos 1984/85 y 1985/86. Su trabajo docente en dicho centro finalizaría en el curso 1986/1987. Sobre la docencia impartida, Iturrate recuerda una gran actividad práctica, largas jornadas laborales, que resultaban en proyectos audiovisuales que llevaban el aula al exterior del centro, a las localizaciones donde producían las prácticas de realización. Una enseńanza enfocada al cine, a su lenguaje y práctica, con un marcado acento hacia la fotografía. Dichos estudios, por otra parte, se convertirían en los primeros estudios oficiales en los que se imparten con carácter obligatorio asignaturas de Historia y Teoría del cine, que Iturrate desarrollaría posteriormente, también, en su actividad como docente en la ULL a partir del curso 1988/89.

Del mismo modo, durante el curso siguiente, 1987/88, Iturrate se encarga de implantar en el IES Politécnico de Las Palmas los mismos estudios de Imagen y Sonido ya establecidos en Tenerife. Sin embargo, pese a ocupar desde entonces la Jefatura del Seminario de Imagen y Sonido en dicho centro, su labor se interrumpe al ańo siguiente cuando ingresa en la Universidad de La Laguna como profesor

42 Toda la información referente a la relación de Luis Fernando de Iturrate Cárdenes y la implantación de los grados de Imagen y Sonido de formación profesional en Canarias se ha encontrado en la documentación oficial aportada por el propio Fernando de Iturrate, a falta de una respuesta por parte de la Consejería de Educación, así como de localizar información al respecto en el $B O E$ y/o el $B O C$. 
asociado a tiempo completo. Así se convierte en el primer docente de la ULL en el departamento de Ciencias de la Información que pertenece al área de conocimiento de Comunicación Audiovisual y Publicidad.

De esta forma comenzaron los primeros estudios profesionales oficializados en Canarias sobre el mundo audiovisual. No obstante, la oferta de formación profesional no se ha desarrollado enormemente, y el siguiente hito de marcada relevancia lo encontramos en 1993. Con la LOGSE ya en marcha, aquel año se inauguran los primeros estudios de relacionados con el área de Imagen y Sonido en el IES La Guancha. Ese curso se pondría en marcha el módulo experimental Mantenimiento y operaciones técnicas de equipos de radio y televisión, que impartirían cinco profesores del Departamento de Electrónica durante tres cursos consecutivos.

Luego, en el curso 1996/97, y tras haber visitado varios centros del territorio peninsular -con especial relevancia el IES Puerta Bonita, el Instituto Oficial de Radio Televisión Española y la Escola de Imaxe e Son de La Coruña- se monta el Ciclo Superior de Realización de Audiovisuales y Espectáculos, con el respectivo Departamento de Comunicación, Imagen y Sonido, y un grupo completo de profesores. De esta forma se oficializa uno de los estudios más alabados en los años siguientes dentro y fuera del territorio insular.

De la actividad desarrollada en el IES La Guancha hay bastante información en su Libro 25 aniversario, accesible desde la web oficial del centro. Sobre los estudios de Imagen y Sonido hay varias referencias a proyectos de realización, presentación a concursos cinematográficos o a iniciativas de intercambios de estudiantes. De tal manera que al centro se le ha aplaudido por la innovación y los buenos resultados de algunas de sus iniciativas, entre las que se encuentra la recreación de escenas clásicas de cine, que les valió, en 2014, para ser merecedores del XXIX Premio Nacional Francisco Giner de los Ríos, a la práctica que mejor facilita la incorporación al mundo profesional y social de los estudiantes.

Por último, habría que apuntar que los estudios de formación profesional ofertados en los tres centros citados en este subapartado no han logrado satisfacer las necesidades formativas que presenta la comunidad autónoma. Si bien han permitido profesionalizar el sector, no han conseguido abordar la formación cultural y artística que se requieren para el fortalecimiento de la cinematografía canaria, siendo indiscutible la necesidad de estudios universitarios de Comunicación Audiovisual, y de una Escuela de Cine, para llegar a contar con tal formación dentro de nuestro territorio.

Así pues, el currículo de los estudios de Imagen y Sonido en formación profesional ha ido evolucionando, incluyendo nuevos grados superiores. En la actualidad la oferta se reparte de la siguiente manera: 


\begin{tabular}{|c|c|c|c|}
\hline Grado & $\begin{array}{c}\text { IES } \\
\text { La GUANCHa }\end{array}$ & $\begin{array}{l}\text { IES Politéctico } \\
\text { Las Palmas }\end{array}$ & $\begin{array}{c}\text { CIFP } \\
\text { CÉSAR Manrique }\end{array}$ \\
\hline $\begin{array}{l}\text { Técnico en Vídeo, Disc-jockey } \\
\text { y Sonido (grado medio) }\end{array}$ & Sí & Sí & No \\
\hline $\begin{array}{l}\text { Técnico superior en Animaciones } \\
\text { 3D, Juegos y Entornos Interactivos }\end{array}$ & No & No & Sí \\
\hline $\begin{array}{l}\text { Técnico superior en Iluminación, } \\
\text { Captación y Tratamiento de } \\
\text { Imagen }\end{array}$ & Sí & Sí & No \\
\hline $\begin{array}{l}\text { Técnico superior en Producción de } \\
\text { Audiovisuales y Espectáculos }\end{array}$ & No & Sí & Sí \\
\hline $\begin{array}{l}\text { Técnico superior en Realización de } \\
\text { Proyectos Audiovisuales } \\
\text { y Espectáculos }\end{array}$ & Sí & Sí & Sí \\
\hline $\begin{array}{l}\text { Técnico superior en Sonido para } \\
\text { Audiovisuales y Espectáculos }\end{array}$ & Sí & Sí & No \\
\hline
\end{tabular}

Fuente: elaboración propia (datos: Consejería de Educación del Gobierno de Canarias).

\subsection{Otras INICIATIVAS DidÁcticas EN El CONTEXTO DE LA LOGSE}

La década de los 90 supuso la antesala perfecta a la sociedad del cambio. En lo mediático, a la sucesiva llegada de televisiones autonómicas desde principios de los 80 -TV3 y ETB 1 comenzarían sus emisiones en 1983 y 1982 respectivamente- se le sumaba ahora el despertar de las nuevas cadenas generalistas privadas, que comienzan sus emisiones en 1990 -Antena 3 lo hace el 25 de enero, Telecinco el 3 de marzo y Canal+ (España) el 8 de junio-. El nuevo panorama mediático coincide además con una reducción de espectadores y salas cinematográficas a nivel nacional, así como el número de títulos realizados por año, debido a la estrategia planteada por el modelo de la Ley Miró de Cine. Sin embargo, lo audiovisual, ampliado entonces a la esfera de lo mediático, genera un mayor impacto en la sociedad, y la necesidad de educar a un público crítico urge.

En ese momento, y tras dos décadas de pocos cambios en el escenario educativo, el Gobierno socialista de Felipe González aprueba la Ley Orgánica 1/1990, de 3 de octubre, de Ordenación General del Sistema Educativo, conocida popularmente como la LOGSE. Este nuevo ordenamiento vendría a modificar algunas asperezas aún permanentes del franquismo, actualizando su presentación a un contexto democrático y europeísta, según la realidad española de aquel momento. Sin embargo, pese a que se restructuran los niveles educativos y se establece un nuevo currículo, se pierde la oportunidad entonces de incluir activamente las enseñanzas audiovisuales y mediáticas en las aulas.

Este hecho se debe, principalmente, a la consideración que se tiene del cine y del objeto audiovisual como herramienta pedagógica, y no como materia a estudiar y desarrollar de manera práctica. Así mismo, este hecho se agrava en el caso de los estudios cinematográficos, ya que no están considerados dentro de esta ley como 
parte de las enseñanzas artísticas, entra las que sí se incluye a la música, la danza, el arte dramático, las artes plásticas y el diseño. Todo ello conduce al inmovilismo en cuanto a la educación audiovisual reglada.

No obstante, la LOGSE incorpora el concepto de transversalidad, el cual vendría a servir a los centros para incluir en las programaciones anuales aquellos contenidos que quedaban fuera de los currículos reglados. El sexo, el medioambiente, la igualdad de género, los hábitos saludables y otras materias, serían trabajados a través de los «temas transversales». El cine también encontró su espacio en este escenario. Pese a que la transversalidad podía garantizar incluso un mayor éxito pedagógico por parte de los alumnos, quienes no se enfrentan a los contenidos con el temor de una evaluación, sino por medio de la experiencia, lo cierto es que su aplicación es discutible.

Por un lado, hay que apuntar a la desigualdad. Se da el caso de centros con profesorado implicado y enormes recursos que pueden desarrollar exitosamente una gran variedad de temas transversales, y al mismo tiempo realidades más crudas, donde la escasez de recursos o la poca participación del profesorado dificultan la puesta en práctica de los temas transversales. Por lo tanto, no se podía garantizar que todo el alumnado pudiera disfrutar de las distintas enseńanzas guiadas por medio de la transversalidad. Así mismo, en ocasiones la buena intención del docente por introducir un tema transversal produce un flaco beneficio a su materia y a las enseñanzas de dicho tema, en cuanto que en ocasiones se requiere de un planteamiento pedagógico guiado que conduzca al éxito.

En este sentido, y volviendo a la realidad canaria, desde la década anterior Yaiza Borges realizó una actividad importante en la creación de cursillos de cine para docentes. Estos cursillos seguirían realizándose desde entonces, como ya se apuntó anteriormente; sin embargo, a finales de los 80 la Consejería de Educación, basándose en algunos modelos llevados a cabo en otras regiones, y sin tener un planteamiento muy claro en cuanto al modelo pedagógico a seguir (tampoco en el caso de esas otras comunidades autónomas), pone en funcionamiento su programa de enseñanzas audiovisuales.

Estos programas tienen en todas las CC.AA. generalmente dos ramas, y en ocasiones tres. Estas serían:

- Formación del profesorado.

- Producción de medios audiovisuales (contenidos).

- Asesoramiento a centros ${ }^{43}$.

43 Estas iniciativas consistían en servir de soporte asesor a los centros que deseaban montar espacios para la realización o reproducción de medios audiovisuales, como teatros, salas de proyección o estudios de radio. No fueron tan frecuentes y relevantes como la formación del profesorado y la producción de medios audiovisuales. 
En cualquier caso, el asesoramiento a centros tendría un papel muy secundario ante la actividad desarrollada en los otros dos ámbitos. Este hecho también se produjo en Canarias ante la realidad audiovisual cada vez más incipiente en la sociedad. En este sentido, la labor de formación del profesorado es especialmente destacable y habría que hacer mención de dos brazos musculares en dicha tarea. Por un lado, a través de la UNED y de Agustín García Matilla y Eduardo García Matilla -fueron pioneros en la formación del profesorado- se creó el curso de Medios Audiovisuales de la UNED, el cual permitió formar a muchos docentes de distintas regiones del territorio nacional.

Por otro lado, entre 1988 y 1998, la Consejería pone en funcionamiento una serie de cursos para el profesorado que versaban sobre fotografía, imagen fija (sistemas de proyección), sonido (radio) y vídeo (cine y televisión). Durante estos años, según estima José Pestano, encargado del desarrollo de los cursos, se pudo haber formado a unos 2000 profesores en todo el Archipiélago, lo que vendría a ser entre un 7\% y un $10 \%$ de todo el profesorado existente entonces -Pestano afirma que probablemente él formara a unos 1500 docentes, y el resto correspondería a sus compañeros César Yllera, Nazario Prieto y Felipe Luis, que también impartían cursos- ${ }^{44}$.

Estos cursos se guían a través de estrategias, conocimiento técnico y ejemplificaciones donde se exhibían distintos modelos de utilización de los medios audiovisuales. Lo que se pretendía en estos cursos era ofrecer al profesorado las habilidades y conocimientos necesarios para que luego adaptaran el uso del audiovisual al aula, teniendo en cuenta que las posibilidades estaban sujetas a la transversalidad y el calendario académico de cada materia curricular. Como último apunte, existía en estos cursos una práctica final que se desarrollaba con los alumnos en el aula, y en ocasiones entre el profesorado -estas prácticas finales no contaban con el seguimiento por parte de los responsables de los cursos-.

Lo relevante de esta formación del profesorado es que servía como polea para formar posteriormente al alumnado. Por lo general, se atendía a dos grandes facetas didácticas, y normalmente centrando la atención en una de ellas. Una tenía por objetivo despertar el espíritu crítico del alumnado a partir de saber cómo funcionan los medios; es decir, se centraba en el análisis crítico y no se realizaba ninguna producción audiovisual. La otra, por el contrario, tenía como misión aprender a hacer; es decir, a saber comunicarse a través del audiovisual, lo cual resultaba muy difícil por las complicaciones técnicas del vídeo en la época, lo que fomentó la realización de programas y estudios de radio.

${ }^{44}$ El profesorado en aquella época tenía un enorme interés por formarse en el audiovisual y llevar nuevas experiencias a las aulas. Así lo demuestra la enorme demanda, que no solo agotaba las plazas ofertadas, sino que en ocasiones atendía a «observadores» que se quedaban fuera de las listas. Eran cursos que se realizaban de lunes a viernes, y en un horario continuo al escolar, y había dos cursos: uno de iniciación de 30 horas y otro avanzado de 100 horas. En cualquier caso, y como último apunte, cabría ańadir que no existían grandes diferencias entre las Islas, aunque Tenerife y Gran Canaria contaban con mejor soporte técnico. 
Por último, en cuanto a la producción de medios audiovisuales, hay que apuntar que ocupaba aproximadamente un $70 \%$ de la actividad desarrollada en aquellos años, por delante incluso de la formación del profesorado, que Pestano simula que ronda el $25 \%$. La producción consistía en la realización de productos audiovisuales con un marcado carácter didáctico que luego eran empleados en el aula. Es, en definitiva, la creación de varias colecciones de vídeos que versan sobre distintas temáticas según solicitara la Consejería. Las principales colecciones fueron:

- Canarias Cultura: recogía distintos elementos de la cultura canaria relacionados con el patrimonio, las artes, la pintura, el medioambiente, etc.

- Canarias Didáctica: incluía experiencias, prácticas, contenidos y modelos de intervención que servían para el profesorado; aunque también podía ser empleado directamente en el aula.

- Canarias Experiencias: recogía distintas experiencias educativas realizadas por el profesorado en las aulas.

- Canarias Coedición (puede que la nomenclatura fuera distinta): recogía distintas piezas que se intercambiaban con otras comunidades autónomas.

En cualquier caso, la faceta productora no tendría una incidencia tan notable en lo que sería la educación mediática como sí lo fue la introducción del cine y los medios audiovisuales por parte de los profesores que eran formados previamente. Esta cultura de suplir las deficiencias del currículo reglado a través de los temas transversales u otras iniciativas individuales (por parte de los docentes) o colectivas (por parte de los centros) perduró durante todo el periodo de la LOGSE y ha continuado hasta nuestra actualidad.

\subsection{LA LOE Y LA LOMCE: NUEVAS ORDENACIONES Y POCOS CAMBIOS}

Después de que la LOGSE circulara durante tres lustros, y tras haber afrontado las legislaturas de Felipe Gonzáles (1982-996) y José María Aznar (1996-2004), el sistema educativo español se reordena a través de la Ley Orgánica 2/2006, de 3 de mayo, de Educación, conocida como LOE, y saliente del Gobierno socialista de José Luis Rodríguez Zapatero. Sin embargo, con el cambio de Gobierno en noviembre de 2011, y las políticas regresivas impuestas por la jefatura popular de Mariano Rajoy, en 2013 se aprueba la Ley Orgánica 8/2013, de 9 de diciembre, para la mejora de la calidad educativa (LOMCE), que vendría a modificar diversos apartados de la LOE.

En cualquier caso, y sin entrar en detalle, lo que vendría a modificar la LOMCE sería todo aquello relacionado con la educación en valores y las nuevas materias de Educación para la Ciudadanía que había incluido la LOE. Del mismo modo, se comprueba cómo las disciplinas de artes y humanidades pierden un peso curricular importante en los distintos niveles, y se fomentan enseñanzas ligadas al emprendimiento, las prácticas profesionales y la tecnología. Así mismo, se pretende establecer un sistema de reválidas para pasar de nivel educativo, o nuevas exigencias 
para recibir dotaciones de becas - muchas de estas medidas han sido congeladas o suprimidas por las protestas populares de la sociedad y el sector educativo-.

Sea como fuere, lo que aquí se trata, que es analizar su implicación en la educación y enseñanzas del audiovisual en Canarias, cabe señalar que la LOE (y por ende la LOMCE) ofreció al audiovisual una mayor importancia dentro de la regulación educativa; ya fuera añadiendo alguna nueva materia, actualizando el currículo de alguna ya existente o incluyendo su uso y conocimiento como objetivos de etapa. De alguna forma, al igual que ocurre con otro tema transversal de la LOGSE como es la ética y los valores cívicos, el audiovisual (que no el cine) coge peso en el sistema educativo español. Sin embargo, en el caso del audiovisual sus contenidos siempre están sujetos a asignaturas optativas o unidades didácticas de materias durante la primaria y el primer ciclo de secundaria obligatoria -al contrario que ocurre con Educación para la Ciudadanía, que es de carácter obligatorio durante el periodo de la LOE; luego la LOMCE la reformularía y la dejaría marginada como materia optativa-.

Pese a todo, resulta positivo comprobar la importancia formal que el texto dota a las habilidades comunicativas y audiovisuales en una sociedad dominada por la imagen y las nuevas herramientas que ofrecen Internet y las TIC. En el artículo 17 de la LOE, que marca los objetivos de la educación primaria, se puede leer en su apartado «j» lo siguiente: «j) Utilizar diferentes representaciones y expresiones artísticas e iniciarse en la construcción de propuestas visuales y audiovisuales». Así mismo, en el artículo siguiente, que trata sobre la organización de dicha etapa, se especifica en el punto 6 que el uso de las TIC y la comunicación audiovisual han de estar presentes en todas las áreas ${ }^{45}$. Esto significa, sí, que lo audiovisual, más allá de conformar un área en sí misma, continúa funcionando a través de la transversalidad o, incluso, de la interdisciplinariedad.

En cuanto a los contenidos curriculares, en primer lugar, habría que destacar que los currículos de Canarias añaden una materia de libre configuración autonómica que es susceptible de atender contenidos de educación audiovisual y mediática - esta sería Prácticas Comunicativas y Creativas-. De esta forma, y con el fin de visualizar mejor la incidencia que el audiovisual tiene en la LOE y la LOMCE, se muestra a continuación la relación de materias ofertadas en el currículo de la ESO y bachillerato en la Comunidad Autónoma Canaria:

\begin{tabular}{lcc}
\multicolumn{1}{c}{ Materia } & LOE & LOMCE \\
\hline Educación Plástica, Visual y Audiovisual & Optativa ESO & Optativa $1 .{ }^{\circ}, 3 .{ }^{\circ}, 4 .{ }^{\circ}$ ESO \\
\hline Cultura Audiovisual I & $1 .{ }^{\circ}$ bach. modalidad & $1 .^{\circ}$ bach. modalidad \\
\hline
\end{tabular}

45 «6. Sin perjuicio de su tratamiento específico en algunas de las áreas de la etapa, la comprensión lectora, la expresión oral y escrita, la comunicación audiovisual, las Tecnologías de la Información y la Comunicación, el emprendimiento y la educación cívica y constitucional se trabajarán en todas las áreas». Ley Orgánica 2/2006, de 3 de mayo, de Educación, p. 24. 


\begin{tabular}{lcc}
\hline Cultura Audiovisual II & $2 .^{\circ}$ bach. modalidad & $2 . .^{\circ}$ bach. modalidad \\
\hline Prácticas Comunicativas y Creativas & - & Libre configuración $1 .{ }^{\circ}, 2 .^{\circ}$ ESO \\
\hline Imagen y Sonido & - & Optativa $2 .^{\circ}$ bach. \\
\hline Fuente: elaboración propia. & &
\end{tabular}

Si bien es cierto que la incorporación de estas materias es relevante, en cuanto que se ofrece al alumnado la posibilidad de poder cursar durante su formación no superior estudios relacionados con la cultura audiovisual predominante en su contexto histórico, es necesario recalcar el carácter no troncal de las mismas. Esto quiere decir que no se garantiza que todos los alumnos vayan a cursar estos estudios, ya sea porque no sientan atracción por estas optativas o modalidades de bachillerato, o bien porque los centros a los que acuden no oferten algunas de estas asignaturas.

Dicho esto, y volviendo a incidir en la idea de que durante la última década ha habido una mejora en la atención dada al mundo de los medios audiovisuales, es oportuno realizar una serie de observaciones:

1. En primer lugar, este aumento de atención se debe al enorme crecimiento de popularidad e incidencia en nuestras vidas que tienen las TIC y los medios de comunicación de masas (incluyendo entre ellos a Internet).

2. En segundo lugar, pese a que estas materias incorporan contenidos curriculares que atienden a esta realidad, lo cierto es que los temas transversales, o mejor dicho, las propuestas interdisciplinares entre materias, así como los proyectos de centros, siguen siendo el principal motor de lo audiovisual y lo mediático en las aulas.

3. Además, en otro orden de las cosas, el término «digital» y su relación con las TIC ha terminado por fagocitar lo audiovisual o mediático, incluyendo estos términos (podríamos decir «clásicos») dentro de su área. Este hecho se concreta en el nuevo sistema de evaluación por competencias, que no incluye una "competencia mediática o audiovisual», pero sí considera estas habilidades y conocimientos en la competencia digital.

4. En el caso de Canarias, existen una serie de iniciativas de carácter autonómico que refuerzan la introducción del audiovisual en las aulas. Concretamente, son destacables el programa de Educar la Mirada, el festival cinematográfico Cinedfest y la acción llevada por algunos festivales de marcada relevancia en el Archipiélago.

\subsection{Educar la Mirada y Cinedfest}

Como vemos, la historia de la educación audiovisual en Canarias no ha contado con un capítulo especial en cuanto a iniciativas oficializadas por las administraciones públicas. Los avances mostrados en los últimos diez años atienden a la necesidad de renovarse ligeramente ante los cambios acelerados de la sociedad y, por otro lado, a responder ante las directrices marcadas desde Europa. Sin embargo, y al 
igual que ha ocurrido en otros territorios, el Archipiélago ha contado con múltiples iniciativas individuales y colectivas que han acercado el audiovisual y el cine a las aulas. En ocasiones por medio del interés del profesorado, y en otros casos gracias al surgimiento de iniciativas que han sido apoyadas por la Consejería de Educación, como son, las ya mencionadas Educar la Mirada y Cinedfest.

En cuanto a Educar la Mirada ya se detallaron varios aspectos de su origen, funcionamiento y objetivos en el apartado de Antecedentes teóricos, y en cualquier caso, no se podría añadir mucha más información a la ya detallada por Gabriel Trenzado Quintero en su trabajo Educar la Mirada: análisis de un proyecto, citado entonces. No obstante, sí es oportuno apuntar que el proyecto nacería durante los últimos años de la LOGSE, y daría sus últimos pases con la inauguración de la LOE y los recortes presupuestarios incitados por la inminente crisis económica de 2008.

Durante los seis cursos en los que estuvo activa esta iniciativa, tutelada por Josep M. Vilageliu y apoyada por la Consejería de Educación, los Centros de Profesores y Filmoteca Canaria (entre los cursos 2002/03 y 2007/08), participaron más de 60000 alumnos según los datos oficiales. Una suma importante de alumnos que pudieron disfrutar de las actividades de cinefórum y el acercamiento a un cine alejado de las corrientes mainstream y que les enseñaba a entender y relacionarse con el séptimo arte de una manera distinta y atendiendo a aspectos críticos y analíticos del audiovisual y su lenguaje. Sin duda, una experiencia cuya pérdida todavía se siente en la actualidad.

No obstante, tras los años más arduos de la crisis económica, los recortes en educación y cultura, el ataque institucional a la cinematografía y el enorme avance de las TIC y la reducción de la brecha digital, en 2014 surge el Festival Educativo de Cine Cinedfest. Dirigido por el cineasta tinerfeño David Cánovas, y con la dirección adjunta del compositor Antonio Hernández, a partir de enero de 2014 comienzan su actividad apoyados por el Gobierno de Canarias y el Cabildo de Tenerife.

Durante el transcurso de aquella primera edición se fueron realizando las guías didácticas a medida que se desarrollaban las clases presenciales en los centros solicitantes. Los centros tenían a su disposición, no solo la docencia en el aula (previa solicitud), sino los materiales en el portal web de Cinedfest ${ }^{46}$. El éxito de la experiencia se reflejó en la participación de 106 centros educativos en toda Canarias. Desde entonces, las cifras no han dejado de escalar.

El proyecto de Cinedfest tiene como objetivo acercar el mundo del audiovisual a los estudiantes que cursan estudios desde primaria hasta formación profesional, mostrándoles todo lo que conlleva la realización de un producto audiovisual (sea una película, un videoclip, un anuncio o cualquier otra creación). Para ello ofrecen a los centros inscritos la posibilidad de recibir clases presenciales, además de emplear las guías didácticas recogidas en el portal web. Así mismo, todos aquellos centros participantes que lo deseen pueden concursar en su festival de cortometrajes - deben presentar un corto de ficción de una duración máxima de siete minutos, así como

${ }^{46}$ La web oficial de Cinedfest es http://www.cinedfest.com/. 
un cartel y la ficha técnica correspondiente ${ }^{47}-$, que concede premios a las mejores películas y labores individuales.

De esta forma, el proyecto de Cinedfest consigue concienciar al alumnado del valor que tiene una producción audiovisual -lo cual permite mejorar el reconocimiento de estos contenidos en un contexto donde la piratería y la baja cultura audiovisual del espectador español ha decapitado al sector cinematográfico-, fomentar el trabajo en equipo, estrechar la relación con el profesorado que recibe la formación de manera conjunta al alumnado y, por supuesto, desarrollar un aprendizaje relacionado con la práctica audiovisual, así como con el apartado técnico de la misma.

Con respecto a esto último, si en el caso de Educar la Mirada se apuntaba que sus contenidos didácticos reforzaban la actitud crítica y analítica del estudiante, esto es, aprender a leer, analizar e interactuar con una película o cualquier contenido audiovisual, en el caso de Cinedfest lo que se alimenta es lo técnico y lo práctico. Esto quiere decir que ambas iniciativas por individual cojean; sin embargo, la conjunción de ambas podría dar lugar a una enseñanza completa en el audiovisual.

En cualquier caso, y volviendo al proyecto de Cinedfest, hay que apuntar que su faceta de festival tiene que ver con el éxito cosechado durante las cuatro ediciones que se han celebrado hasta el momento. El festival permite a los alumnos desarrollar un proyecto audiovisual, compartirlo en la red, mostrárselo a familiares, amigos y extraños, y concursar con su trabajo. Por otro lado, cabe mencionar que las piezas nominadas ${ }^{48}$ son proyectadas en la sala 8 de los Cines Yelmo Meridiano (Tenerife) en una gala final en la que se reparten premios y asisten algunos estudiantes y profesores en representación de los centros. Además, las películas ganadoras son emitidas en Televisión Canaria en la programación de septiembre.

Todo esto sería, en resumen, lo que caracteriza al proyecto de Cinedfest, que, además, desde su segunda edición permite la participación de centros de la Península, para los cuales no se dispone de clases presenciales, y además se colabora igualmente con algunos centros iberoamericanos. Durante las cuatro ediciones que se han celebrado hasta el momento, el número de centros y profesores participantes ha ido aumentando. Esto se debe, en primer lugar, a que los centros que participan en una edición suelen repetir en la siguiente y, en segundo lugar, los profesores participantes que cambian de centro suelen proponer este proyecto en sus nuevos destinos.

Del mismo modo, el número de cortometrajes presentados durante cada edición ha ido aumentando, hasta alcanzar en la presente edición la enorme cifra de 366 películas. En total, durante estas cuatro ediciones se han desarrollado 1167 cortometrajes y 464 clases presenciales, lo que refleja el éxito y la magnitud del proyecto. Para entender mejor cómo se traducen estas cifras, en el caso de la cuarta edición se realizaron en Canarias un total de 142 clases presenciales (unas 700

${ }^{47}$ La realización de un cortometraje permite utilizar el audiovisual como herramienta interdisciplinar con la que trabajar distintos conceptos de materias diferentes.

${ }_{48}$ Durante las tres primeras ediciones había 40 finalistas, 10 por categoría. En la 4. a edición que se celebra actualmente, habrá 48 finalistas, 12 por categoría. 
horas), de la que se aprovecharon más de 5000 alumnos. Por lo tanto, estamos ante una iniciativa a considerar en el plano de la educación audiovisual. En cualquier caso, y como prueba de la evolución experimentada por el Cinedfest, los datos de participación serían los siguientes:

\begin{tabular}{|c|c|c|c|c|c|}
\hline \multicolumn{6}{|c|}{ DATOS DE PARTICIPACIÓN DE CINEDFEST (CUATRO PRIMERAS EDICIONES) } \\
\hline & 1. ${ }^{a}$ EDICIÓN & 2. ${ }^{a}$ EDICIÓN & 3. ${ }^{a}$ EDICIÓN & $4 .^{a}$ EDICIÓN & TOTAL \\
\hline N. ${ }^{\circ}$ centros canarios & 106 & 136 & 158 & 204 & 604 \\
\hline N. ${ }^{\circ}$ docentes canarios & 136 & 176 & 194 & 259 & 765 \\
\hline N.o centros peninsulares & - & 84 & 70 & 64 & 218 \\
\hline N.o clases presenciales & 88 & 97 & 137 & 142 & 464 \\
\hline
\end{tabular}

Fuente: elaboración propia (datos facilitados por la dirección de Cinedfest).

\begin{tabular}{|c|c|c|c|c|c|}
\hline \multicolumn{6}{|c|}{ CORTOMETRAJES PRESENTADOS A CINEDFEST (CUATRO PRIMERAS EDICIONES) } \\
\hline $\begin{array}{c}\text { Niveles } \\
\text { Educativos }\end{array}$ & 1. ${ }^{\mathrm{a}}$ EDICIÓN & 2. ${ }^{a}$ EDICIÓN & 3. ${ }^{a}$ EDICIÓN & 4. ${ }^{a}$ EDICIÓN & TOTAL \\
\hline Primaria & 33 & 22 & 33 & 42 & 130 \\
\hline ESO & 68 & 106 & 140 & 114 & 428 \\
\hline Bachillerato & 36 & 53 & 77 & 122 & 288 \\
\hline FP y CEPA & 23 & 24 & 26 & 33 & 106 \\
\hline Península* & - & 60 & 66 & 55 & 181 \\
\hline Iberoamérica* & - & 10 & 11 & 13 & 34 \\
\hline Total & 160 & 275 & 353 & 379 & 1167 \\
\hline
\end{tabular}

Fuente: elaboración propia (datos facilitados por la dirección de Cinedfest).

* El número de cortometrajes procedentes de centros peninsulares o iberoamericanos es la suma de los proyectos presentados en distintos niveles educativos. Sin embargo, dado el carácter de este trabajo, centrado en Canarias, no se ha mostrado el desglose.

\subsection{La EdUCACión AUdiovisual NO FORMAL EN CANARIAS}

Hasta el momento se han analizado dos facetas distintas de la formación audiovisual en Canarias. Hablábamos de una enseñanza artesanal antes de la década de los 80, así como de una serie de iniciativas profesionalizadas desarrolladas fundamentalmente por Yaiza Borges, que constituirían una parte de las enseñanzas no formales que se ofertaron en el Archipiélago. Por otro lado, hemos comprobado cómo desde los años 80 comienzan a instalarse en la escuela (en el antiguo BUP) y en la formación profesional los primeros estudios relacionados con el audiovisual; estas enseñanzas formales han ido incrementándose hasta gozar de un mayor protagonismo en la actualidad.

Sin embargo, aunque a partir de los ańos 80 podamos dar cuenta de una regulación por parte de la Consejería de Educación en lo que son los estudios de 
audiovisuales, lo cierto es que durante todo el tiempo que ha transcurrido desde entonces han seguido dándose otras iniciativas formativas fuera de las aulas; algunas de ellas apoyadas por instituciones públicas, y otras de estricto carácter privado. Estas iniciativas se encuentran suscritas a las programaciones de algunos festivales cinematográficos, a algunos espacios culturales de las Islas o simplemente a eventos que de forma más bien aleatoria se celebran en el Archipiélago.

\section{Festivales de cine}

En primer lugar, sería destacable mencionar los cursos y talleres que han surgido alrededor de algunos festivales cinematográficos que se celebran en las Islas. Concretamente, son dignos de mención el Festival Internacional de Cine Documental de Guía de Isora MiradasDoc, el Festival Internacional de Cine de Las Palmas de Gran Canaria, el Festival Internacional de Cine Medioambiental de Canarias FICMEC, el Festivalito de La Palma o Animayo. Todos estos festivales, además de otros que no han sido mencionados, han complementado su programación de películas con distintos talleres y cursos que transcurren durante la celebración del festival. Además de esto, en muchos casos los tres institutos de FP que ofrecen estudios de Imagen y Sonido en las Islas participan activamente durante el festival, ya sea de manera profesional o por medio de concursos o asistencia de dichos talleres y cursos.

Dicho esto, es justo destacar la labor didáctica de la que ha gozado el Festivalito de La Palma desde sus inicios en 2002. Este festival se caracteriza por fomentar la creación de una pieza audiovisual que debe desarrollarse durante la semana de celebración del festival para su sección La Palma Rueda. Esta labor creativa se construye bajo un lema elegido que define cada edición, y en los equipos de rodaje en ocasiones se unen distintos profesionales y cineastas amateurs que comparten sus conocimientos y destrezas. Pese a no presentar un formato didáctico en sí mismo, su papel ha sido determinante en la formación artesanal de algunos cineastas del boom que se vivió la década pasada, y también, pero en menor medida, de la que surge en la actualidad -hay que tener en cuenta que el festival sufrió varios años de parón debido a la crisis económica-.

Del mismo modo, alrededor de MiradasDoc se celebra a lo largo de todo el año el Laboratorio de Desarrollo de Documentales de Creación, CreaDoc. Esta iniciativa, que surgió como un brazo derivado del Laboratorio de Escritura Audiovisual (LEAC) en 2011, ha estado coordinado por Andrés Koppel y Rolando Díaz. Durante varios meses se ayuda a una serie de autores escogidos por concurso a desarrollar sus proyectos documentales, ofreciéndoles formación y consejo profesional. La iniciativa ha permitido el desarrollo de algunos proyectos. 


\section{Centros de formación no reglada}

A lo ya comentado se le une una serie de iniciativas de carácter público, y en ocasiones privado, que han ofertado, a lo largo de las últimas dos décadas, numerosos cursos y talleres relacionados con el audiovisual. No se pretende hablar aquí de la labor desempeñada por algunos actores que han mantenido su relación con la docencia a través de cursos durante este tiempo, sino más bien de aquellas propuestas que han gozado de una estructura más duradera y estable. No quiere decir esto que las otras iniciativas no merezcan atención, ya que han sido muchos los cursos y talleres privados, organizados incluso por cuenta propia, que se han realizado durante estos años.

Así pues, es justo mencionar tres espacios que han mantenido una oferta atractiva y constante sobre el audiovisual, focalizada principalmente a la profesionalización del sector en las Islas. Estos serían: Gran Canaria Espacio Digital, Sociedad de Promoción de Gran Canaria y Escuelas Artísticas de Los Realejos (Tenerife).

Lo primero que llama la atención es que los tres espacios se encuentran repartidos entre las islas capitalinas, lo que explica el aún más bajo nivel de formación existente en el resto del territorio canario. Por otro lado, en el caso de Gran Canaria Espacio Digital y la Sociedad de Promoción de Gran Canaria se trata de instituciones públicas apoyadas por el Cabildo de Gran Canaria, a diferencia de las Escuelas Artísticas de Los Realejos, que es de iniciativa privada, pese a contar con el apoyo del Ayuntamiento.

Pese a todo, estos centros han mantenido una nutrida oferta formativa relacionada con el audiovisual. En el caso de Gran Canaria Espacio Digital es indiscutible, ya que ha venido realizando una tarea constante en la organización de cursos y talleres desde los años 90, además de ofrecer en sus instalaciones material de visionado, así como equipos de montaje y soporte técnico. En el caso de la Sociedad de Promoción de Gran Canaria, dentro de todos sus cursos ofertados, ha dedicado en los últimos tiempos un apartado al sector audiovisual, para el que ofrece talleres y cursos especializados, normalmente orientados a la vida profesional. Por último, en el caso de las Escuelas Artísticas de Los Realejos, se han ofrecido en algunas ediciones cursos completos, normalmente de nueve meses de duración (de octubre a junio) sobre Realización Audiovisual o Postproducción de Cine y Vídeo Digital, siendo lo más parecido a una escuela de cine y compitiendo o complementando la oferta de formación profesional.

\subsection{LA EDUCACIÓN EN LA UNIVERSIDAD Y OTROS APUNTES MÁS}

Finalmente, antes de finalizar este recorrido por la formación audiovisual ofertada en Canarias, resulta necesario seńalar una serie de cuestiones pertinentes a la oferta de la educación superior. En el Archipiélago existen dos universidades públicas, la Universidad de La Laguna (ULL) y la Universidad de las Palmas de Gran Canaria (ULPGC), así como tres universidades privadas, la Universidad Europea de Canarias (UEC), la Universidad Fernando Pessoa-Canarias (UFP-C) y la Universidad 
del Atlántico Medio (UNIDAM). Estos centros se reparten, nuevamente, entre las dos islas capitalinas, encontrándose la ULL y la UEC en Tenerife, y la ULPGC, la UFP-C y la UNIDAM en Gran Canaria; de tal manera que los estudios superiores se concentran en dichos territorios ${ }^{49}$.

Por otro lado, hay que destacar que hasta 1989 la ULL fue el único centro universitario del Archipiélago. Luego, en ese curso, y con una enorme polémica política y social, se fundó la ULPGC. Sin embargo, la juventud de la ULPGC no se ha visto recompensada con la introducción de un grado de Comunicación Audiovisual; manteniendo al territorio canario huérfano de los estudios superiores universitarios vinculados al audiovisual.

De este modo, y coincidiendo con las nuevas regulaciones educativas (la LOE y la LOMCE), en octubre de 2012 comenzarían a impartirse los primeros cursos de la UEC, entre los que convendría destacar el grado de Comunicación Publicitaria por su relación académica con los estudios de audiovisuales. Por su parte, la gran novedad llegó en el curso 2016/17, con la incorporación de la UFP-C y sus estudios de grado de Periodismo, grado de Comunicación Audiovisual y el doble grado de Periodismo y Comunicación Audiovisual. Del mismo modo, la aparición de la UNIDAM en el curso 2017/18 con sus estudios de grado de Cine y grado de Comunicación ha venido a ampliar el espectro formativo de la educación superior relacionada con la comunicación audiovisual y sus variantes.

Ante este hecho hay que lamentar que la universidad privada haya conquistado estos estudios antes que las dos universidades públicas del Archipiélago. No obstante, por otro lado, es una suerte que la UFP-C y la UNIDAM hayan creado estos grados, posibilitando que los estudiantes interesados no se vean obligados a escapar al territorio peninsular para formarse -en cualquier caso, el bajo número de plazas ofertadas por curso, así como el carácter privado de la UFP-C y la UNIDAM, no solventa el problema-.

Por otro lado, atendiendo a la oferta de máster, esta ha contado con algunos títulos relacionados con el mundo audiovisual ofertados desde la ULL o la ULPGC. $\mathrm{Si}$ atendemos a la oferta actual de la ULPGC, se oferta el máster universitario en Cultura Audiovisual y Literaria; por su parte, la ULL actualmente no cuenta con ningún máster relacionado. No obstante, es de destacar la ambición por parte de algunos profesores de la ULL por ofertar máster en crítica cinematográfica, guion u otras especialidades. Este interés se vio reflejado en 2013 a través del máster en Guion Cinematográfico que se impartió con la colaboración de la entonces Escuela Superior de Cine de Canarias (ya desaparecida) durante dos ediciones.

Finalmente, y a falta de un estudio más detallado, no habría que olvidar que tanto en la ULL como en la ULPGC, en algunos grados se imparten asignaturas (normalmente de carácter optativo) relacionadas con el audiovisual, y más concretamente con el cine. Si bien es cierto que en el caso de la ULL esta oferta de

49 Algunas titulaciones también se imparten en otras islas, como el grado de Enfermería de la ULL, que además de poder cursarse en Tenerife se puede estudiar en La Palma. 
asignaturas se ha visto perjudicada por la normativa de Bolonia, que ha fomentado la cohesión de alguna de ellas, o incluso en otros casos se han eliminado asignaturas por la selección de estudios que determinan los departamentos y facultades.

Del mismo modo, hay que destacar, al menos en el caso de la ULL, la presencia de distintos docentes, doctores e incluso un catedrático -Fernando Gabriel Martín se convirtió en 1995 en el primer catedrático de Historia del Cine y Medios Audiovisual de la ULL ${ }^{50}$ - que han sido los principales responsables de impulsar estas asignaturas en el seno de la universidad, así como el Aula de Cine, de la que ya se habló con anterioridad.

Por todo ello, y dada la evolución y las necesidades del sector audiovisual en las Islas, es urgente que alguna de las universidades públicas del territorio canario oferte nuevas titulaciones de grado y máster relacionadas con la Comunicación Audiovisual; todo apunta a que la ULL sería la más adecuada para tal labor al contar ya con la antigua Facultad de Ciencias de la Información, además de extender estos estudios a las dos provincias canarias.

Para acabar este apartado, y aunque no se trata de un centro de estudios universitario, hay que reseñar que en el marco de la 17. ${ }^{a}$ edición del Festival Internacional de Cine de Las Palmas, celebrado en abril de 2017, se presentó el Instituto del Cine de Canarias, un centro privado dependiente del Instituto del Cine de Madrid (fundado en 2002). Dicho instituto ofrecerá distintas diplomaturas a partir del curso 2017/18 en su centro ubicado en la capital grancanaria. De momento la oferta presentada se compone de la diplomatura de Interpretación Cine/Tv (tres años de duración), la diplomatura de Maquillaje y Caracterización (dos años de duración) y los estudios comunes del primer año de otras diplomaturas que dan acceso posterior a las mismas. Habrá que esperar para comprobar cómo ha sido la aceptación y los resultados del Instituto del Cine de Canarias; de momento es sospechoso que las diplomaturas ofertadas estén ligadas a la creación del personal que en muchas ocasiones buscan y solicitan los rodajes extranjeros y nacionales.

\section{CONCLUSIONES}

No cabe duda de que en 2017 vivimos sumergidos en aquello que llaman la era de la información. Desde que nos despertamos hasta que activamos las alarmas en nuestro smartphone nos encontramos rodeados de imágenes, iconos que conquistan el espacio de lo cognitivo en nuestra mente. En este escenario de la hiperconectividad y la burbuja informativa, lo mediático se ha establecido de forma permanente en la

${ }^{50}$ El nombramiento de la Cátedra de Fernando Gabriel Martín se puede consultar en la Resolución de 15 de mayo de 1995, de la Universidad de La Laguna, por la que se nombra, en virtud de concurso, a don Fernando Gabriel Martín Rodríguez catedrático de universidad en el área de conocimiento de «Historia del Arte» (BOE núm. 138, de 10 de junio de 1995). 
esfera de lo influyente; es decir, los medios, sean del tipo que sean, interactúan con nosotros como sujetos de una sociedad inestable.

Ante la influencia de los medios, de la imagen, del sonido, del audiovisual, cabe esperar que el éxito para intentar esquivar o cuestionar su hegemonía en la construcción de los imaginarios colectivos pase por la educación de la ciudadanía. Esta educación ha sido reclamada en España desde la aparición de la televisión allá por la década de los 50 del pasado siglo. Sin embargo, aún en la actualidad no se le reconoce el valor formativo que se merece, quedando estas enseñanzas marginadas a las iniciativas individuales de profesores, algunos centros o a la suerte de algunas asignaturas optativas o vinculadas a una rama académica.

En este sentido, desde los años 70, y con más énfasis en los 80 , la educación audiovisual, o la comunicación audiovisual -dos nomenclaturas para referirse prácticamente a lo mismo - tuvo un enfoque centralizado en el cine, como el medio de masas más influyente en las décadas directamente anteriores. Sin embargo, a medida que ha pasado el tiempo, y con la llegada de las televisiones privadas y de pago, el medio televisivo ha ido acaparando, cada vez más, mayor popularidad y número de espectadores. Del mismo modo, en los últimos tres lustros, Internet, como escenario de lo digital, se ha convertido en el medio representante de nuestro presente y futuro inmediato.

No obstante, aunque los medios y canales de difusión hegemónicos han ido cambiando, el lenguaje y la comunicación apenas han presentado variaciones considerables. Es por esta razón por la que se podría pensar que el estudio de lo audiovisual tiene hoy igual o mayor vigencia que antes de la irrupción de la web 2.0. Dicho de otro modo, la necesidad que requieren los estudios sobre lo audiovisual, o si se prefiere, sobre lo mediático, son en nuestra actualidad más necesarios que nunca, ante la enorme influencia que ejercen estos medios en la sociedad. Hay que educar en lo audiovisual, desde una perspectiva global, esto es, teniendo en cuenta su carácter mediático, productor de contenidos y digital.

No podemos continuar viviendo engańados por la creencia de que las nuevas generaciones comprenden y saben hacer un buen uso de los medios audiovisuales únicamente por saber pulsar sobre el icono rojo de «rec» en la pantalla de su dispositivo «inteligente». Del mismo modo que un conductor no tiene por qué tener idea de mecánica solo por saber manejar un coche, el ciudadano medio no es conocedor, y mucho menos experto, del audiovisual solo por saber grabar un vídeo y subirlo a Internet, o incluso, en el mejor de los casos, por haberse empapado de varias filmografías y series ofertadas en los nuevos videoclubes online.

La importancia que tiene hoy la educación audiovisual es, si se me permite afirmarlo, mayor que la que tuvo hace veinte o treinta ańos. La masiva recepción de mensajes a través de la publicidad, los programas de televisión, las películas y series, así como los contenidos de blogs, convierte a los sujetos en seres más débiles e influenciables hoy que entonces. ¿Se puede dudar entonces de la necesidad de educar a la ciudadanía en lo audiovisual, mediático y digital? Solo por medio de una formalización de la educación audiovisual, mediática y digital se podrá lograr dotar a la ciudadanía de los necesarios conocimientos y habilidades que la equipen con el escepticismo y la crítica necesaria sobre la que puede descansar una democracia sana. 
En Canarias, tal y como se ha visto a lo largo de los distintos apartados de este trabajo, esa educación no se ha logrado establecer en el currículum escolar. De hecho, en ocasiones la oferta ha sido más abundante fuera del sistema reglado, por parte de iniciativas privadas o colectivas. Comprobamos cómo hasta los años 80 solo existía en el territorio insular una enseñanza artesanal, o en el mejor de los casos, una formación enfocada en lo cinematográfico ofrecida por asociaciones de cineastas amateurs, como fue el caso del Colectivo Yaiza Borges.

A partir de entonces, el recorrido de esas iniciativas ajenas al sistema educativo (talleres y cursos) se complementaría con una lenta introducción del audiovisual en el currículo de la educación reglada. En 1983 surgen los primeros estudios de imagen y sonido en formación profesional en Tenerife, ese mismo curso se comienza a ofertar en algunos institutos una optativa sobre cine en los cursos de BUP, y algo más tarde, a partir de los 90 y la aprobación de la LOGSE, el cine, lo audiovisual y lo mediático se instalarían en la escuela por medio de los «temas transversales».

La transversalidad, hoy evolucionada hacia la interdisciplinariedad, ha sustituido con éxito a las propuestas de incluir en el currículo una nueva materia que tratara los contenidos relacionados con lo audiovisual, lo mediático y (ahora) lo digital. De hecho, pese a que la LOE y la LOMCE han incluido algunas materias optativas, la realidad descubre que no todo el alumnado tiene la suerte o el derecho de recibir esa formación. La transversalidad y la interdisciplinariedad han tenido como aliados en Canarias algunas propuestas educativas apoyadas con las administraciones públicas, como han sido el caso de Educar la Mirada o Cinedfest. Sin embargo, ninguna de estas propuestas, por sí solas, dota al alumnado de un conocimiento global, crítico y práctico sobre lo audiovisual, y mucho menos sobre lo mediático en la era digital.

Hoy, igual que ayer, las aulas canarias hacen un mayor uso de los contenidos audiovisuales como herramientas educativas, en lugar de objetos de estudio. El profesor de Física proyecta una escena de Big Bang Theory para explicar el Efecto Doppler; sin embargo, pese a que ese uso puede beneficiar a los estudios de física, el profesor, y probablemente los alumnos, no cuestionan ni son conscientes de los contenidos machistas, conservadores y raciales contenidos en este popular y exitoso producto televisivo. Del mismo modo, la transversalidad en pocas ocasiones cuestionará estos mensajes, o se basará en la creación de un contenido audiovisual para entender sus posibilidades mediáticas y coercitivas.

Por otro lado, vimos de igual manera que la educación superior en Canarias no responde adecuadamente a la necesidad profesional de formar expertos en comunicación audiovisual y digital. Por el contrario, la oferta actualmente se restringe a unos pocos grados superiores de FP, los estrenados grados de Comunicación Audiovisual en la Universidad privada Fernando Pessoa-Canarias y la Universidad del Atlántico Medio, y algunos cursos y talleres que se programan desde centros públicos como Gran Canaria Espacio Digital. Si bien, la enseñanza técnica no siempre garantiza una verdadera educación en el uso de las mismas, al menos en lo teórico y esencial del elemento audiovisual como objeto de estudio.

En cualquier caso, debemos considerar que la escuela $-\mathrm{y}$ entiéndase por escuela especialmente las etapas de primaria y secundaria obligatoria- representa el 
espacio educativo por el que pasa todo el conjunto de la sociedad. Esta realidad implica que la educación de la ciudadanía ha de realizarse en su contexto, dado que la escuela es la única institución que puede garantizar una educación concreta y formal. Dicha educación debe estar soportada, no solo por los conocimientos esenciales de la ciencia, las humanidades y los estudios lingüísticos, sino también por otros, aún más importantes en lo que se refiere a la salud de nuestra sociedad democrática, como son los valores éticos, la economía y la política, los medios de comunicación y la salud.

La escuela tradicional ha relegado estos últimos conocimientos a los temas transversales de la LOGSE, o a las actuales competencias que marcan el sistema de evaluación de materias concretas (ya que no suelen estar presentes entre las competencias básicas y comunes a todo el currículo). Considero por tanto que la creación de materias como Educación para la Ciudadanía supone un intento por solventar los claros déficits que han acompañado a la transversalidad y la interdisciplinariedad. Quizá debamos a empezar a comprender que para el grueso de la población, y en definitiva para la sociedad, es más importante educar en valores, salud y democracia que en contenidos referentes al aprendizaje memorístico de mapas políticos, análisis sintácticos y morfológicos o fórmulas matemáticas de trigonometría. El futuro de la educación debe dotar al individuo de la autonomía crítica, racional y cognitiva suficiente como para poder cuestionar lo que se recoja en los libros de texto, en páginas web o en la pantalla de su televisor o su smartphone.

En definitiva, y regresando a la realidad pertinente en Canarias, podemos afirmar que, en efecto, la sociedad canaria no ha dispuesto, ni dispone en la actualidad, de las necesarias incorporaciones, al currículo de las educaciones formales obligatorias y superiores, de las enseñanzas destinadas al estudio y práctica del medio audiovisual, más concretamente al cinematográfico; suponiendo tal realidad un grave déficit en la formación de su ciudadanía y profesionales. De este modo, habría que puntualizar que, pese a que el currículo canario y la oferta formativa son muy pobres en cuanto a educación audiovisual y/o mediática, ha existido una evolución positiva (ya señalada con anterioridad), aunque insuficiente, que tendremos que tener en cuenta. El éxito o el fracaso del Instituto de Cine Canarias o de los estudios ofertados por las nuevas universidades privadas marcará en buena medida el estado de esta cuestión en los próximos años.

Por esta razón, y a falta de una revisión de este trabajo que sea capaz de añadir información más concreta respecto a la oferta no reglada por la Administración, así como de los estudios superiores, se añade a continuación una recomendación para mejorar la atención que desde la educación formal se hace al audiovisual.

En primer lugar, habría que aceptar que la educación audiovisual y/o mediática no depende de la tecnología presente en cada contexto social e histórico, sino más bien del uso y el lenguaje que se emplea en la producción, realización y distribución/exhibición de contenidos. Teniendo esto en cuenta, lo audiovisual y mediático siempre va a estar presente en la comunicación analógica y en la comunicación digital. Por lo tanto, a la hora de hablar de comunicación digital, o de las competencias digitales, debemos dar cuenta de que lo fundamental de las mismas se encuentra en lo audiovisual y lo mediático, no en el medio que se emplee como soporte en las distintas fases de producción. 
Aclarado este punto, y teniendo en cuenta que la Consejería de Educación del Gobierno de Canarias tiene un marco de libertad restringido en cuanto a la configuración del sistema educativo, realizo la siguiente propuesta:

- Reformular la materia de libre configuración autonómica presente en $1 .^{\circ}$ y $2 .^{\circ}$ de ESO.

- Pasaría a llamarse Comunicación Audiovisual y Mediática.

- Contenidos teóricos ligados al lenguaje audiovisual y la observación crítica y analítica de los contenidos y medios de comunicación (prensa, radio, televisión e Internet).

- Contenidos prácticos en relación con los conceptos teóricos y con un claro objetivo de capacitar al alumnado para poder expresarse adecuadamente haciendo un buen uso de los medios (fomentando el carácter digital y multimedia de Internet).

- Obligatoriedad de recibir clases, talleres, charlas de profesionales del sector que muestren a través de su experiencia la importancia de saber relacionarse adecuadamente con los medios.

- El peso de la evaluación debe encontrarse en los resultados prácticos, no en los cuestionarios teóricos. Se debe ejercitar la reflexión por delante de la memorización de conceptos.

- Introducir distintos elementos de la comunicación mediática y digital a través de actividades interdisciplinares impartidas por todas las materias desde primaria hasta bachillerato. Se trata de cumplir y respetar lo que dicta actualmente la Competencia Digital.

- Dotar a los centros con una filmoteca (puede ser a través de copias digitales o físicas) que contenga una relación de títulos adecuados para el empleo en el aula. Estos títulos estarían acompañados de una guía docente con información sobre el contenido de la película, ficha técnica y datos históricos y artísticos de las películas.

- Recuperar el proyecto Educar la Mirada corrigiendo sus déficits y actualizándolo, de tal manera que, junto con Cinedfest, ofrezcan a todos los centros del Archipiélago un complemento ideal para los estudios curriculares.

- Plantear un proyecto de formación por etapas educativas que plantee las enseñanzas que Cinedfest ofrece durante un año escolar en el desarrollo de varios cursos consecutivos. Dicho proyecto debería tener un planteamiento teórico y práctico apoyado por la filmoteca escolar y la colaboración directa de profesionales del sector audiovisual en las aulas.

- Introducir en los estudios superiores habilitantes para ejercer la docencia de primaria y secundaria una asignatura que sustituya con el tiempo a los actuales cursos de formación. Esta asignatura se centraría en ofrecer al profesorado un conocimiento crítico y práctico esencial para la ejecución de las actividades interdisciplinares. 
- Apoyar la introducción del grado de Comunicación Audiovisual en alguna de las universidades públicas y mejorar la oferta formativa de los grados superiores de FP.

- Estudiar la construcción de una Escuela de Cine apoyada por Filmoteca Canaria y Canarias Cultura en Red que ofrezca formación técnica y teórica sobre el cine y el audiovisual, teniendo en cuenta la historia y la realidad profesional del Archipiélago. En esta escuela se podrían aunar los esfuerzos dados desde algunos festivales y proyectos como el de CreaDoc. En su defecto, extender las becas y los lazos de colaboración con otras escuelas instaladas en otras regiones del Estado español.

Esta propuesta surge del convencimiento de quien escribe de la necesidad que nuestra sociedad presenta ante el déficit de ciudadanos capaces de defenderse de la enorme influencia que ejercen los medios de comunicación. Siendo conscientes de que la realidad educativa en Canarias resulta aún más pobre que en otras regiones españolas, al menos en cuanto a lo audiovisual se refiere, es oportuno valorar el recorrido histórico aquí descrito, así como los principales aciertos y errores de los hitos señalados. No quepa duda de que la salud de un pueblo es consecuencia de la salud de su educación. Si el cine e Internet deben enseñar algo a las nuevas generaciones, esto deberá ser en virtud de defender y mejorar una sociedad de valores, democracia y libertad. 


\section{BIBLIOGRAFÍA}

Alegre Paiz, A. (2016): El documental canario en la era digital. Trabajo final de grado de Comunicación Audiovisual, Getafe, Universidad Carlos III de Madrid.

Ambrò, A. y Breu, R. (2011): 10 ideas clave. Educar en medios de comunicación. La educación mediática, Barcelona, Graó.

Ambrós, A. y Breu, R. (2007): Cine y educación. El cine en el aula de primaria y secundaria, Barcelona, Graó.

Area, M. y Pessoa, T. (2012): «De lo sólido a lo líquido: Las nuevas alfabetizaciones ante los cambios». Comunicar. Revista Científica de Comunicación y Educación. 38, pp. 13-20.

Ballesta, J., Sancho , J. \& Area, M. (1998): Los Medios de Comuicación en el Curriculum, Murcia, Editorial KR.

Bergala, A. (2007): La Hipótesis del Cine. Pequeño tratado sobre la transmisión del cine en la escuela $y$ fuera de ella. Barcelona, Laertes.

Cabrera Déniz, D. (1999): «Mujeres isleñas de Tenerife abasteciendo carbón a barcos de la escuadra»: una incógnita en la producción Lumière de 1896», Actas del VIII Congreso de la Asociación Española de Historiadores de Cine.

Carnero Hernández, A. \& Pérez-Alcalde Zárate, J.A. (2011): El cine en Canarias (Una revisión critica), Madrid, T\&B Editores.

Cervera, J. (1977): Otra escuela. Cine/Radio/T.V./Prensa, Madrid, Editorial S.M.

Fernández Ibáñez, J. y Socorro Duaso, M. (1982): El cine en el aula, Madrid, Narcea.

Fernández, C. (1973): Iniciación al lenguaje del cine, Valladolid, Heraldo.

AA.VV. (2004): Yaiza Borges: aventura y utopia, Gobierno de Canarias.

Gabriel Martín, F. y Fernández Arozena, B. (1997): Ciudadano Rivero: La Rivero Film y el cine mudo en Canarias, San Cristóbal de La Laguna, Excmo. Ayuntamiento de San Cristóbal de La Laguna.

Grupo Comunicar (1998): Comunicar. Revista de Educación en Medios de Comunicación. N. ${ }^{\circ}$ 11: El cine en las aulas, Andalucía, Grupo Comunicar.

IES La Guancha (2004): Instituto de Educación Secundaria de La Guancha. XXV aniversario de su fundación. Una historia única de la perseverancia y la superación. Recuperado el 15 de mayo de 2017, de http://www.ieslaguancha.es/wp/wp-content/uploads/Libro25Aniversario/ files/assets/basic-html/page1.html. Libro blanco del audiovisual canario, (2007). Canarias.

López, J. y Vilageliu, J.M. (2009): «El cortometraje en Canarias durante la primera década del siglo XXI». Latente 7: Revista de Historia y Estética Audiovisual, pp. 139-235.

Ministerio de Educación y Ciencia (1971): Catálogo de la Cinemateca educativa, Madrid, Servicio de publicaciones del Ministerio de Educación y Ciencia.

Morales Quintero, S. y Modolell Koppel, A. (1997): Un siglo de producción de cine en Canarias (1987/1997), Las Palmas de Gran Canaria, Cabildo Insular de Gran Canaria.

Pérez-Alcalde Zárate, J.A. (2005): Los cine-clubes Universitario y Náutico [1953-1969], Filmoteca Canaria, Prensa, radio, cine y televisión en familia. (1965). Madrid, Sociedad de Educación Atenas. 
Sebastián Lozano, J. (coord.) (2009): El Audiovisual y la educación para el desarrollo. Del entretenimiento a la participación, Valencia, Fundación Mainel.

SÉGuin, J.-C. (2007): «La enseñanza del cine en el sistema educativo francés», Comunicar. Revista Científica de Comunicación y Educación, pp. 21-25.

Trenzado Quintero, G. (2016): Educar la Mirada: análisis de un proyecto. Trabajo final de máster de Cultura Audiovisual y Literatura, Universidad de Las Palmas de Gran Canaria.

Vilageliu, J. (1977): «Didáctica del cine», La Tarde, 12 de marzo de 1977, p. 17.

\section{ANEXO DE LEGISLACIÓN Y JURISPRUDENCIA}

Ley 14/1970, de 4 de agosto, General de Educación y Financiamiento de la Reforma Educativa (BOE núm. 187, de 6 de agosto de 1970).

Ley Orgánica 1/1990, de 3 de octubre, de Ordenación General del Sistema Educativo (BOE núm. 238, de 4 de octubre de 1990).

Resolución de 15 de mayo de 1995, de la Universidad de La Laguna, por la que se nombra, en virtud de concurso, a don Fernando Gabriel Martín Rodríguez, Catedrático de Universidad en el área de conocimiento de «Historia del Arte» (BOE núm. 138, de 10 de junio de 1995).

Ley Orgánica 10/2002, de 23 de diciembre, de Calidad de la Educación (BOE núm. 307, de 24 de diciembre de 2002).

Ley Orgánica 2/2006, de 3 de mayo, de Educación (BOE núm. 106, de 4 de mayo de 2006).

Ley Orgánica 8/2013, de 9 de diciembre, para la mejora de la calidad Educativa ( $B O E$ núm. 295, de 10 de diciembre de 2013).

Ley 6/2014, de 25 de julio, Canaria de Educación no Universitaria (BOE núm. 238, de 1 de octubre de 2014). 